\title{
Empirical cross-sectional asset pricing: a survey
}

\author{
Amit Goyal
}

Published online: 24 December 2011

(C) Swiss Society for Financial Market Research 2011

\begin{abstract}
I review the state of empirical asset pricing devoted to understanding crosssectional differences in average rates of return. Both methodologies and empirical evidence are surveyed. Tremendous progress has been made in understanding return patterns. At the same time, there is a need to synthesize the huge amount of collected evidence.
\end{abstract}

Keywords Empirical asset pricing · Factor models · Time-series regressions · Cross-sectional regressions · Anomalies

\section{JEL Classification G12 · G14}

\section{Introduction}

One of the central questions in finance is why different assets earn different rates of return. It has long been understood that while most of the day-to-day variation in returns may be due to constant arrival of information, asset pricing models can contribute to our understanding of why the average rates of return vary across securities. All asset pricing models agree on the central insight that returns are compensation for bearing systematic risk. What they differ on is what constitutes systematic risk. Finance is also one of few fields of economics that has the good fortune of having abundant data that are generated naturally. The development of theory has, therefore, gone hand-in-hand with empirical analysis. As Campbell (2000) puts it: "Theorists develop models with testable predictions; empirical researchers document "puzzles"- -stylized facts that fail to fit established theories - and this stimulates the development of new theories."

\footnotetext{
A. Goyal ( $\varangle)$

Swiss Finance Institute, University of Lausanne, 1015 Lausanne, Switzerland

e-mail: Amit.Goyal@unil.ch
} 
This paper is a survey of empirical literature on cross-sectional asset pricing. In this introduction, I discuss various choices that I made regarding the scope and structure of this survey. First, there is no attempt to review the theory behind asset pricing models; the goal of the survey is purely empirical in nature. Second, I restrict my attention (at least in the evidence section) to stocks. Other asset classes, such as fixed-income and derivatives, are not treated in this survey. Even my discussion of the literature on pricing of equities does not cover all areas. For example, I hardly make any mention of the pricing of aggregate market (equity premium) or the performance of delegated portfolio management. Of course, given the cross-sectional nature of the survey, no attempt is made either to review the time-series predictability literature. Third, I have tried to devote equal attention to the methodological approaches in applied empirical asset-pricing work and to the enormous empirical evidence on return patterns. At the same time, neither any proofs or formal derivations for methods are presented, nor do I attempt to cite magnitudes and/or their statistical significance of results in the empirical section. The benefit of being lax in details is that it allows me to be broader.

I have no doubt that in spite of my best efforts, I have omitted several important papers on both approaches and results. The omissions are not a result of any conscious decision to signify the lack of importance of certain strands of literature and/or to impose my personal preferences; they are in all cases inadvertent. Finally, there are several other excellent reviews of asset pricing in the literature. For example, see Campbell (2000), Fama and French (2004), Jagannathan et al. (2010a, 2010b), Subrahmanyam (2010), and Cochrane (2011). Each of these reviews has its own strengths and I highly recommend all of them. My hope is that my review complements these excellent articles by being a bit more comprehensive in the area of empirical crosssectional asset pricing.

The remainder of this article is structured as follows. Section 2 reviews the various approaches to testing asset pricing models. Section 3 presents an overview of the empirical evidence on returns. I discuss empirical tests of asset pricing models as well as anomalies that defy explanations from these models in this section. Section 4 concludes with some thoughts on the agenda for the future.

\section{Methodology}

The two main approaches for testing asset pricing models are time-series regressions (TSR) and cross-sectional regressions (CSR). These two approaches are complementary; asset pricing models impose the same restrictions on both testing approaches. At the same time, though, one of these statistical frameworks might offer advantages in terms of implementation and/or flexibility. Which approach one uses is often left to individual tastes. Testing for consistency of results from both these approaches is, unfortunately, rare but highly recommended (Lewellen et al. 2010). It is also possible to combine TSR and CSR into a unified generalized method of moments (GMM) framework; sometimes this facilitates derivation of analytical results (Cochrane 2005). In this section, I review all these methodological approaches to testing asset pricing models. 


\subsection{Factor selection}

The selection of which factors and how many factors is, of course, a prerequisite important topic. I briefly discuss three common ways of dealing with this issue. Interested readers are referred to references for a more comprehensive discussion on factor selection. The first approach to identifying factors uses theory and economic intuition. The most celebrated asset pricing model is capital asset pricing model (CAPM) of Sharpe (1964), Lintner (1965a), and Mossin (1966) which identifies the return on the market portfolio as the only common factor, exposures to which determine expected returns. Merton's (1973) intertemporal capital asset pricing model (ICAPM) significantly advances this theory. Any state variable that predicts future investment opportunities serves as a state variable. For example, Chen et al. (1986) use macroeconomic variables (term premium, default premium, inflation, and industrial production growth) as additional factors. Breeden's (1979) consumption capital asset pricing model (CCAPM) provides further economic underpinnings to asset pricing by relating asset returns to their covariances with marginal utility of consumption. Lettau and Ludvigson (2001a, 2001b) posit that consumption-to-wealth-to-income ratio, cay, is a state variable that follows from CCAPM.

The second approach to factor selection is statistical. These approaches are motivated by the arbitrage pricing theory (APT) of Ross (1976). Factor analysis (Anderson 2003) can be used to analyze the covariance structure of returns. This approach yields estimates of factor exposures as well as returns to underlying factors (which are linear combinations of returns on underlying assets). Lehmann and Modest (1988, 2005) provide more details on this approach. An alternative statistical approach is principal component analysis. Connor and Korajczyk $(1986,1993)$ develop a methodology for extracting principal components from a large cross section of returns when the number of time-series observations is smaller than the cross-sectional dimension.

The third approach is to create factors based on firm characteristics. The firm characteristics are motivated by return anomalies. The most famous example of this approach is the three-factor model of Fama and French (1993), based on size and value anomaly. These three factors are sometimes augmented with a momentum factor (Carhart 1997) based on momentum anomaly.

I will discuss the performance of alternative factor models in the empirical section of this review. For expositional purposes and to develop the intuition for the testing approaches, I consider a generic $K$-factor model in the remainder of this section.

\subsection{Theory}

Denote the return during period $t$ on asset $i$ by $R_{i t}$. The number of assets is $N$ and the number of time periods is $T$. Frequently in real life, especially when dealing with individual securities, one does not have balanced panels in the sense that returns are available for all assets for all time periods. Some of the methods described below can adapt to this reality very easily with few modifications while other methods are not amenable to unbalanced panels. In the latter case, researchers use a few portfolios for which the entire time-series of returns can be constructed. I proceed with the theory in this subsection without considering this complication. In later subsections, I will note the situations where unbalanced panels can create problems. 
Returns on factor $k$ are denoted by $F_{k t}$. Let $\mu$ be the $N \times 1$ vector of expected returns on the assets and $\lambda$ be the $K \times 1$ vector of factor risk premiums. All asset pricing models aim to explain the cross-sectional variation in expected returns across assets. This variation is explained by exposures to factors. In other words, the asset pricing restriction is

$$
\mu=\iota \lambda_{0}+B \lambda,
$$

where $\iota$ is a conforming vector of ones and $B$ is an $N \times K$ matrix of factor loadings/betas. It is often assumed that this multi-beta factor model relation follows naturally from Ross's (1976) APT. However, the original version of APT derives only an approximate relation between expected returns and betas. One usually needs additional assumptions of competitive equilibrium (Connor 1984, and Grinblatt and Titman 1985) to derive equality (1). See Shanken (1982, 1985a, 1992a) and Roll and Ross (1984) for further discussion of the difference between approximate and exact versions of (1). Another justification of multi-beta pricing models follows from ICAPM. As mentioned before, any state variable that predicts future investment opportunities serves as a state variable/factor in the above equation.

The restriction (1) can be further modified depending on whether or not a risk-free asset is available and/or whether the factors are traded portfolios. For example, in the presence of a risk-free asset and factors that are traded (with expected returns given by a $K \times 1$ vector $\mu_{F}$ ), the asset pricing relation is given by

$$
\mu=\iota R_{f}+B\left(\mu_{F}-\iota R_{f}\right),
$$

where $R_{f}$ is the risk-free rate of return. For the special case of CAPM, this equation reduces to the well-known formula for expected returns often used in capital budgeting:

$$
\mu_{i}-R_{f}=\beta_{i}\left(\mu_{M}-R_{f}\right),
$$

where $\mu_{M}$ is the return on the market index, and $\beta_{i}$ is the market beta of the $i$ th asset given by $\beta_{i}=\operatorname{cov}\left(R_{i t}, R_{m t}\right) / \operatorname{var}\left(R_{M t}\right)$.

As mentioned before, asset pricing models are inherently cross-sectional in nature and naturally impose cross-sectional pricing restrictions. These models can also be adapted to derive restrictions of the time-series properties of each asset's returns. Therefore, in principle, either TSR or CSR methods could be used for testing asset pricing models regardless of the nature of factors. However, as will be seen shortly, TSR is more suitable for the case of traded factors (especially with a risk-free asset). CSR is more versatile and especially suited to non-traded factors.

There are two other considerations to note at this stage. First, I have made an implicit assumption of the absence of time-varying moments in the above equations. CAPM is a single-period model and, for testing purposes, so is ICAPM with deterministic investment opportunity sets. Conditional asset pricing models require additional machinery to deal with them and are discussed towards the end of this section. Second, most of the econometric methods and the standard errors of estimators shown in this review are derived under the assumption that the null of the asset pricing model is true. The reader is referred to Shanken (1985b), Shanken and Zhou (2007), and Kan et al. (2011) for distributional theory under model misspecification. 


\subsection{Time-series approach (factors are traded portfolios)}

I start with the case of traded factors and a risk-free asset. ${ }^{1}$ In this case, the asset pricing restriction is given in (2). The interest is in checking the validity of this equation. Since in any finite sample the equation is unlikely to hold even if the asset pricing model is correct, one would like to calculate pricing errors and derive their distribution. Of course, one is also interested in factor risk premiums. As we will shortly see, the latter is a relatively straightforward task in this setting. It is useful to note at the outset that the methods presented in this section are useful for (a) balanced panels, and (b) small number of test assets. Thus the test statistics are only $T$-consistent. Asset pricing tests involving a large number of individual securities are best done using cross-sectional methods, outlined in the next subsection, even for the case where the factors are traded portfolios.

The most common way to estimate the asset pricing model is to run an unconstrained TSR such as

$$
R_{t}=\alpha+B F_{t}+\varepsilon_{t},
$$

where $R_{t}$ is the $N \times 1$ vector of excess stock returns at time $t$ (this is a slight abuse of notation for convenience; I used $R_{t}$ to denote raw stock returns in the previous section) and $F_{t}$ is the $K \times 1$ vector of factor returns (assumed to be excess returns of zero-cost portfolios). It is not strictly necessary to impose further distributional restrictions on the TSR residual $\varepsilon$. We start by assuming that these residuals are iid over time and relax this assumption later. Further assume that $\operatorname{var}(\varepsilon)=\Sigma_{\varepsilon}$. The unknown parameters are then $\alpha, B$, and $\Sigma_{\varepsilon}$. Since the explanatory variables are the same for each asset, the SUR framework leads to estimating (4) asset by asset. The estimates of the unknown parameters and their standard errors are given by:

$$
\begin{aligned}
\widehat{\alpha} & =\widehat{\mu}-\widehat{B} \widehat{\mu}_{F}, \\
\widehat{\alpha} & \sim N\left[\alpha, \frac{1}{T}\left(1+\mu_{F}^{\prime} \Sigma_{F}^{-1} \mu_{F}\right) \Sigma_{\varepsilon}\right] \\
\widehat{B} & =\left[\sum_{t=1}^{T}\left(R_{t}-\widehat{\mu}\right)\left(F_{t}-\widehat{\mu}_{F}\right)^{\prime}\right]\left[\sum_{t=1}^{T}\left(F_{t}-\widehat{\mu}_{F}\right)\left(F_{t}-\widehat{\mu}_{F}\right)^{\prime}\right]^{-1}, \\
\operatorname{vec}(\widehat{B}) & \sim N\left[\operatorname{vec}(B), \frac{1}{T} \Sigma_{F}^{-1} \otimes \Sigma_{\varepsilon}\right] \\
\widehat{\Sigma_{\varepsilon}} & =\frac{1}{T} \sum_{t=1}^{T}\left(R_{t}-\widehat{\alpha}-\widehat{B} F_{t}\right)\left(R_{t}-\widehat{\alpha}-\widehat{B} F_{t}\right)^{\prime}, \\
T \widehat{\Sigma}_{\varepsilon} & \sim \mathcal{W}\left(T-2, \Sigma_{\varepsilon}\right),
\end{aligned}
$$

\footnotetext{
${ }^{1}$ The assumption of a risk-free asset is not completely innocuous. Black (1972), for example, derives a version of CAPM without the risk-free asset. The estimation of zero-beta rate, however, poses nontrivial challenges in a time-series context. See Kandel (1984) and Shanken (1986) for maximum likelihood approach to this problem and Campbell et al. (1997) for a more comprehensive treatment. These estimation complications are not present in CSR, as discussed in the next subsection.
} 
where $\widehat{\mu}=\frac{1}{T} \sum_{t} R_{t}, \widehat{\mu}_{F}=\frac{1}{T} \sum_{t} F_{t}, \widehat{\Sigma}_{F}=\frac{1}{T-K} \sum_{t}\left(F_{t}-\widehat{\mu}_{F}\right)\left(F_{t}-\widehat{\mu}_{F}\right)^{\prime}$, the subscript under the summation sign is to signify that the sum is taken over time periods, and $\mathcal{W}$ is a Wishart distribution. Consistent estimates for the standard errors of the parameters can be obtained by substituting sample values in the expressions for asymptotic variances.

It is important to realize that TSR (4) is an unconstrained regression that does not impose the asset pricing null of $\alpha=0$. In principle, it is possible to obtain more efficient estimates of factor loadings, $B$, by running a constrained regression without intercepts. The unconstrained regression is more robust to model misspecification, so the usual trade-off between efficiency and robustness applies.

\subsubsection{Factor premium}

The factor risk premium is simply the factor mean in this case. Thus $\lambda \equiv \mathrm{E}[F]$. The estimate of the risk premium and its standard error are given by

$$
\widehat{\lambda}=\frac{1}{T} \sum_{t=1}^{T} F_{t} \sim N\left[\lambda, \frac{1}{T} \Sigma_{F}\right] .
$$

If one is interested in joint pricing of factors, one can construct a test statistic for the null hypothesis $\lambda=0$ as

$$
J_{3}=\left(\frac{T-K}{T K}\right) \widehat{\lambda}^{\prime} \operatorname{var}(\widehat{\lambda})^{-1} \widehat{\lambda} .
$$

If one assumes normality of factor returns, $J_{3}$ is distributed as $F(K, T-K)$ in finite samples. An asymptotic test statistic can be constructed as $\widehat{\lambda}^{\prime} \operatorname{var}(\widehat{\lambda})^{-1} \widehat{\lambda}$ which is distributed as $\chi_{K}^{2}$.

\subsubsection{Pricing errors}

The intercepts in (4) are pricing errors. The asset pricing imposes the restriction that all alphas are zero. This across-equation restriction shows the equivalence between the inherently cross-sectional nature of an asset pricing model and TSRs. We can construct a test statistic for the null hypothesis $\alpha=0$ as

$$
J_{1}=\frac{T-N-K}{N}\left(1+\widehat{\mu}_{F}^{\prime} \widehat{\Sigma}_{F}^{-1} \widehat{\mu}_{F}\right)^{-1} \widehat{\alpha}^{\prime} \widehat{\Sigma}_{\varepsilon}^{-1} \widehat{\alpha} .
$$

If one makes the additional assumption of joint normality of returns and factors, Jobson and Korkie (1985) show that finite sample distribution of $J_{1}$ is central $F(N, T-N-K)$. The asymptotic distribution is given by

$$
T\left(1+\widehat{\mu}_{F}^{\prime} \widehat{\Sigma}_{F}^{-1} \widehat{\mu}_{F}\right)^{-1} \widehat{\alpha}^{\prime} \widehat{\Sigma}_{\varepsilon}^{-1} \widehat{\alpha} \sim \chi_{N}^{2} .
$$

Gibbons et al. (1989) provide an intuitive interpretation of the quadratic form $\widehat{\alpha}^{\prime} \widehat{\Sigma}_{\varepsilon}^{-1} \widehat{\alpha}$. They show that

$$
\widehat{\alpha}^{\prime} \widehat{\Sigma}_{\varepsilon}^{-1} \widehat{\alpha}=s r_{q}^{2}-s r_{F}^{2},
$$


where $s r_{q}$ is the Sharpe ratio of the ex post tangency portfolio constructed from the $N$ assets and the $K$ factors and $s r_{F}=\left(\widehat{\mu}_{F}^{\prime} \widehat{\Sigma}_{F}^{-1} \widehat{\mu}_{F}\right)^{1 / 2}$ is the Sharpe ratio of the ex post tangency portfolio constructed from just the $K$ factors. When the ex post tangency portfolio is the same as that constructed from factors, then the quadratic term and the $J_{1}$ statistic will be zero. A decline in the Sharpe ratio of the factor tangency portfolio provides stronger evidence against the asset pricing model under consideration.

\subsubsection{Non-normal/non-iid errors}

As mentioned earlier, strong distributional assumptions are not necessary for most of the asset pricing tests. It is generally more useful to cast the testing framework in a GMM setting for the general case of non-iid or non-normal errors. GMM imposes the natural moment condition:

$$
\mathrm{E}\left[\begin{array}{c}
R_{t}-\alpha-B F_{t} \\
\operatorname{vec}\left(\left(R_{t}-\alpha-B F_{t}\right) F_{t}^{\prime}\right)
\end{array}\right]=\mathrm{E}\left[\begin{array}{c}
\varepsilon_{t} \\
\operatorname{vec}\left(\varepsilon_{t} F_{t}^{\prime}\right)
\end{array}\right]=\left[\begin{array}{c}
0_{N \times 1} \\
0_{N K \times 1}
\end{array}\right] .
$$

Since the number of unknown parameters is equal to the number of moment conditions, the system is exactly identified. The GMM estimates are, therefore, the same as OLS estimates (5)-(6) for unconstrained TSR. Letting $\theta^{\prime}=\left(\alpha^{\prime} \operatorname{vec}(B)^{\prime}\right)$ denote the parameter vector, the variance of the parameter estimates is given by

$$
\operatorname{var}(\widehat{\theta})=\frac{1}{T} d^{-1} S d^{-1^{\prime}}
$$

where

$$
d=-\left[\begin{array}{cc}
1 & \mu_{F}^{\prime} \\
\mu_{F} & \Sigma_{F}+\mu_{F} \mu_{F}^{\prime}
\end{array}\right] \otimes I_{N}
$$

and

$$
S=\sum_{j=-\infty}^{\infty} E\left[\begin{array}{c}
\varepsilon_{t} \\
\operatorname{vec}\left(\varepsilon_{t} F_{t}^{\prime}\right)
\end{array}\right]\left[\begin{array}{c}
\varepsilon_{t-j} \\
\operatorname{vec}\left(\varepsilon_{t-j} F_{t-j}^{\prime}\right)
\end{array}\right]^{\prime} .
$$

There are three remarks to be noted under this setting. First, the risk premium and its standard error are still given as before in (8)-(9). Second, only asymptotic results for pricing error are available in the GMM setting. In particular

$$
T \widehat{\alpha}^{\prime} \operatorname{var}(\widehat{\alpha})^{-1} \widehat{\alpha} \sim \chi_{N}^{2}
$$

which is a generalization of (11). Third, the practical implementation of GMM reduces to Newey and West (1987) corrected standard errors for $\widehat{\alpha}$ and $\widehat{B}$.

\subsection{Cross-sectional approach (factors are non-traded portfolios)}

We now consider the case of non-traded factors. We continue to assume that a riskfree asset exists; however, we allow for the possibility that the zero-beta rate is different from the risk-free rate of return. It is possible to use TSR in this setting to obtain 
estimates of factor risk premia and pricing errors (see Campbell et al. 1997). However, the estimation is greatly simplified by CSR. We continue to assume (a) balanced panels, and (b) small number of test assets.

The basic idea is two-pass regressions. In the first stage, we obtain estimates of betas from the time-series regression:

$$
R_{t}=a+B F_{t}+\varepsilon_{t} .
$$

The second-stage is then a cross-sectional regression of average returns on betas:

$$
\bar{R}_{T}=\widehat{B} \lambda+\alpha
$$

where $\bar{R}_{T}$ is the average sample return and the subscript is meant to denote that the average is calculated over sample length of $T$. Note that in the second-stage regression, $B$ 's are the right-hand side explanatory variables and $\lambda$ 's are the regression coefficients. The time series intercept $a$ in the first stage is not equal to the pricing error as we can no longer claim that $\lambda \equiv \mathrm{E}(F)$. The pricing errors are given by the crosssectional residuals $\alpha$. Since $\alpha$ 's are just the time-series average of the true $\varepsilon$ residuals (not the TSR residuals which are always mean zero), we have $\mathrm{E}\left(\alpha \alpha^{\prime}\right)=\frac{1}{T} \Sigma_{\varepsilon}$. It is possible, nay common, to run regression (18) with an intercept. In this case, the intercept is the zero-beta rate in excess of the risk-free rate. If the theory dictates that the zero-beta rate should be the same as the risk-free rate, then imposing this null of no-intercept leads to more efficient estimates. However, an intercept provides more robust estimates. In what follows, I do not allow for intercepts to reduce notational clutter.

Regression (18) can be estimated using OLS. The appropriate formulas for the factor premia, $\lambda$, and pricing errors, $\alpha$, are:

$$
\begin{aligned}
\widehat{\lambda}_{\mathrm{OLS}} & =\left(\widehat{B}^{\prime} \widehat{B}\right)^{-1} \widehat{B}^{\prime} \bar{R}_{T}, \\
\operatorname{var}\left(\widehat{\lambda}_{\mathrm{OLS}}\right) & =\frac{1}{T}\left(B^{\prime} B\right)^{-1}\left(B^{\prime} \Sigma_{\varepsilon} B\right)\left(B^{\prime} B\right)^{-1}, \\
\widehat{\alpha}_{\mathrm{OLS}} & =\bar{R}_{T}-\widehat{B}_{\mathrm{\lambda}} \widehat{\mathrm{OLS}}, \\
\operatorname{var}\left(\widehat{\alpha}_{\mathrm{OLS}}\right) & =\frac{1}{T}\left(I_{N}-B\left(B^{\prime} B\right)^{-1} B\right) \Sigma_{\varepsilon}\left(I_{N}-B\left(B^{\prime} B\right)^{-1} B\right)^{\prime} .
\end{aligned}
$$

Since the regression residuals $\alpha$ are cross-sectionally correlated, more efficient estimates can be obtained by GLS. The appropriate formulas are:

$$
\begin{aligned}
\widehat{\lambda}_{\mathrm{GLS}} & =\left(\widehat{B}^{\prime} \Sigma_{\varepsilon}^{-1} \widehat{B}\right)^{-1} \widehat{B}^{\prime} \Sigma_{\varepsilon}^{-1} \bar{R}_{T}, \\
\operatorname{var}\left(\widehat{\lambda}_{\mathrm{GLS}}\right) & =\frac{1}{T}\left(B^{\prime} \Sigma_{\varepsilon}^{-1} B\right)^{-1}, \\
\widehat{\alpha}_{\mathrm{GLS}} & =\bar{R}_{T}-\widehat{B} \widehat{\lambda}_{\mathrm{GLS}}, \\
\operatorname{var}\left(\widehat{\alpha}_{\mathrm{GLS}}\right) & =\frac{1}{T}\left(\Sigma_{\varepsilon}-B\left(B^{\prime} \Sigma_{\varepsilon}^{-1} B\right)^{-1} B^{\prime}\right) .
\end{aligned}
$$




\subsubsection{Errors-in-variables}

Since betas in the second-pass CSR (18) are themselves estimated via TSR (17), this creates the well-known econometric problem of errors-in-variables (EIV). This requires correction for the standard errors of the risk premium and pricing error estimates. The following results are due to Shanken (1992b):

$$
\begin{aligned}
& \operatorname{var}\left(\widehat{\lambda}_{\mathrm{OLS}}\right)=\frac{1}{T} \Sigma_{F}+\frac{1}{T}\left(B^{\prime} B\right)^{-1}\left(B^{\prime} \Sigma_{\varepsilon} B\right)\left(B^{\prime} B\right)^{-1} \times\left(1+\lambda^{\prime} \Sigma_{F}^{-1} \lambda\right) \\
& \operatorname{var}\left(\widehat{\alpha}_{\mathrm{OLS}}\right)=\frac{1}{T}\left(I_{N}-B\left(B^{\prime} B\right)^{-1} B\right) \Sigma_{\varepsilon}\left(I_{N}-B\left(B^{\prime} B\right)^{-1} B\right)^{\prime} \times\left(1+\lambda^{\prime} \Sigma_{F}^{-1} \lambda\right) \\
& \operatorname{var}\left(\widehat{\lambda}_{\mathrm{GLS}}\right)=\frac{1}{T} \Sigma_{F}+\frac{1}{T}\left(B^{\prime} \Sigma_{\varepsilon}^{-1} B\right)^{-1} \times\left(1+\lambda^{\prime} \Sigma_{F}^{-1} \lambda\right) \\
& \operatorname{var}\left(\widehat{\alpha}_{\mathrm{GLS}}\right)=\frac{1}{T}\left(\Sigma_{\varepsilon}-B\left(B^{\prime} \Sigma_{\varepsilon}^{-1} B\right)^{-1} B^{\prime}\right) \times\left(1+\lambda^{\prime} \Sigma_{F}^{-1} \lambda\right)
\end{aligned}
$$

There are two differences between these equations and the ones presented previously. One is the presence of a multiplicative term which is the squared Sharpe ratio of the tangency portfolio constructed from the factors using the factor premia, $\lambda$, as the means of factor portfolios. The second is an additive term representing the variance of the factors. In practice, this additive term is more important than the multiplicative term in computation of standard errors of factor risk premia.

One can construct a joint test of asset pricing implication that all the pricing errors, $\alpha$, are zero. This is done similarly to the case when factors are traded portfolios (11) and the exact test statistic is given by

$$
T\left(1+\lambda^{\prime} \Sigma_{F}^{-1} \lambda\right) \alpha^{\prime} \widehat{\Sigma}_{\varepsilon}^{-1} \alpha \sim \chi_{N-K}^{2} .
$$

The degrees of freedom are $N-K$ instead of $N$ because we estimate $\lambda$ from the cross-sectional regression instead of imposing/assuming $\lambda=\mathrm{E}[f]$.

\subsubsection{Non-normal/non-iid errors}

As before, strong distributional assumptions are not necessary for most of the asset pricing tests. The moment conditions are:

$$
\mathrm{E}\left[\begin{array}{c}
R_{t}-a-B F_{t} \\
\operatorname{vec}\left(\left(R_{t}-a-B F_{t}\right) F_{t}^{\prime}\right) \\
R_{t}-B \lambda
\end{array}\right]=\mathrm{E}\left[\begin{array}{c}
\varepsilon_{t} \\
\operatorname{vec}\left(\varepsilon_{t} F_{t}^{\prime}\right) \\
\alpha
\end{array}\right]=\left[\begin{array}{c}
0_{N \times 1} \\
0_{N K \times 1} \\
0_{N \times 1}
\end{array}\right] .
$$

The top moment conditions are similar to those for the time-series case (13). The slight, but important, difference is that the intercept in the first two rows is $a$ and not $\alpha$. The third set of moment conditions is the asset pricing restriction ( $\alpha$ 's are not parameters but the last $N$ moments). The top two moments are exactly identified. The bottom moment is the over-identifying condition as the number of moments is $N$ and the number of parameters is only $K$. If we use a weighting vector $B^{\prime}$ on 
this condition, we obtain OLS estimates; if we use a weighting vector $B^{\prime} \Sigma_{\varepsilon}^{-1}$, we obtain GLS estimates. Let $w$ denote a generic $N \times K$ weighting vector and define an $(N+K+N K) \times(2 N+N K)$ matrix $e$ as

$$
e=\left[\begin{array}{cc}
I_{N+N K} & 0_{(N+N K) \times N} \\
0_{K \times(N+N K)} & w^{\prime}
\end{array}\right] .
$$

Letting $\theta^{\prime}=\left(a^{\prime} \operatorname{vec}(B)^{\prime} \lambda\right)$ denote the parameter vector, the variance of the parameter estimates is given by

$$
\operatorname{var}(\widehat{\theta})=\frac{1}{T}(e d)^{-1} e S e^{\prime}(e d)^{\prime-1}
$$

where

$$
\left.d=-\left[\begin{array}{cc}
1 & \mu_{F}^{\prime} \\
\mu_{F} & \Sigma_{F}+\mu_{F} \mu_{F}^{\prime} \\
& 0_{N \times(N+N K)}
\end{array}\right] \otimes I_{N} \quad 0_{(N+N K) \times N}\right]
$$

and

$$
S=\sum_{j=-\infty}^{\infty} \mathrm{E}\left(\left[\begin{array}{c}
R_{t}-a-B F_{t} \\
\left(R_{t}-a-B F_{t}\right) F_{t} \\
R_{t}-B \lambda
\end{array}\right]\left[\begin{array}{c}
R_{t-j}-a-B F_{t-j} \\
\left(R_{t-j}-a-B F_{t-j}\right) F_{t-j} \\
R_{t-j}-B \lambda
\end{array}\right]\right)^{\prime} .
$$

\subsubsection{Factors are traded portfolios}

There is nothing inherent in the cross-sectional approach that precludes the use of traded factors. One could all the methods described in this subsection even when the factors are traded portfolios. However, it is important to understand that the results from TSR and CSR are not the same for the case of traded portfolios. The factor risk premium is estimated as the sample mean in TSR and the predicted zero-beta rate is the same as the risk-free rate of return. Thus, TSR fits the cross section of returns by a simple line that joins the origin and the factor. The deviations from this line represent the pricing errors for all the other assets; the factors themselves have no pricing error. In contrast, CSR tries to fit the cross section of all asset returns including the factors. OLS regression, for example, picks the slope (factor risk premium) and the intercept (zero-beta rate in excess of risk-free return) to best fit all the points. Lewellen et al. (2010) emphasize that one diagnostic test of an asset pricing model with traded factors is that the risk premia estimate from CSR and TSR should be statistically indistinguishable.

\subsection{Fama-MacBeth}

Fama and MacBeth (1973) pioneered an approach to asset pricing that is very widely used. This is an extension of the two-pass procedure described in the previous section. In the first stage, we obtain estimates of betas from the time-series regression:

$$
R_{t}=a+B F_{t}+\varepsilon_{t}
$$


The second-stage is a cross-sectional regression each time period of returns on estimated betas:

$$
R_{t}=\lambda_{0 t}+\widehat{B} \lambda_{t}+\alpha_{t},
$$

where we have explicitly included the intercept to denote the zero-beta rate in excess of the risk-free rate and $\lambda_{t}$ is the estimated risk premium at time $t$. The second stage regression can be run using OLS, GLS (Shanken 1985b), or WLS using the diagonal elements of $\Sigma_{\varepsilon}$ (Litzenberger and Ramaswamy 1979). Under the null, all three estimators converge to the same limit. The difference from the previous section is that we run this regression each period rather than once with sample average returns. The factor risk premium and pricing error estimates are then given as simple time-series averages of period by period estimates:

$$
\widehat{\lambda}=\frac{1}{T} \sum_{t=1}^{T} \widehat{\lambda}_{t}, \quad \widehat{\alpha}=\frac{1}{T} \sum_{t=1}^{T} \widehat{\alpha}_{t} .
$$

There is surely cross-sectional correlation in pricing errors $\alpha_{i t}$. This is what had prompted us to consider GLS regression in the previous section. However, we do not have to worry about this issue here. The advantage of the Fama-MacBeth procedure is that we do not compute the variances of estimates each period (which would require considerations of cross-correlation) but compute the variance of the average estimates using the time-series of these estimates. In other words, the variance of the estimates is given by

$$
\operatorname{var}(\widehat{\lambda})=\frac{1}{T^{2}} \sum_{t=1}^{T}\left(\widehat{\lambda}_{t}-\widehat{\lambda}\right)\left(\widehat{\lambda}_{t}-\widehat{\lambda}\right)^{\prime}, \quad \operatorname{var}(\widehat{\alpha})=\frac{1}{T^{2}} \sum_{t=1}^{T}\left(\widehat{\alpha}_{t}-\widehat{\alpha}\right)\left(\widehat{\alpha}_{t}-\widehat{\alpha}\right)^{\prime}
$$

There are several advantages of the Fama-MacBeth approach. First, it can easily accommodate unbalanced panels. One uses returns on only those stocks which exist at time $t$, which could be different from those at another time period. Moreover, the distribution of the risk premium estimates does not depend on the number of stocks, which can vary over time. Second, even though we use constant betas, the procedure is flexible to allow for time-varying betas. For instance, Fama and MacBeth (1973) use rolling betas in their analysis although Fama and French (1992) report evidence that use of rolling versus full-sample betas does not yield different inferences. Third, it is possible that autocorrelation in returns (negligible at monthly frequency) leads to autocorrelation in risk premium estimates. This is easily accounted for by NeweyWest type corrections to variance formulas (32).

\subsubsection{Errors-in-variables}

In spite of the intuitive appeal of the Fama-MacBeth procedure, the EIV problem persists because betas in the second stage regression are pre-estimated. Shanken (1992b) provides a correction for this problem under the assumption of normally distributed 
errors. This correction involves a quadratic term, $c=\lambda^{\prime} \Sigma_{F}^{-1} \lambda$, that enters multiplicatively in the expression for the variance of the risk premium estimate as:

$$
T \operatorname{var}_{\mathrm{EIV}}(\widehat{\lambda})=(1+c)\left[T \operatorname{var}(\widehat{\lambda})-\Sigma_{F}\right]+\Sigma_{F},
$$

where $\operatorname{var}(\widehat{\lambda})$ is the Fama-MacBeth variance given in (32). Jagannathan and Wang (1998) provide results for the case where the residuals may exhibit heteroskedasticity and autocorrelation. Many researchers have noted that the standard error correction for the EIV problem matters little in real data when the factors are portfolio excess returns. However, Kan et al. (2011) show that substantial standard error adjustments can be obtained with non-traded factors.

\subsubsection{Characteristics}

Frequently researchers want to test whether stock returns are related to firm characteristics such as size, price-to-earnings ratio, past returns, etc. It is especially easy to check for pricing of characteristics using Fama-MacBeth method. Suppose that we have $L$ firm characteristics for firm $i$ given by $z_{i}$. Then one expands the crosssectional regression in the following way:

$$
R_{t}=\lambda_{0 t}+\widehat{B} \lambda_{t}+Z \gamma_{t}+\alpha_{t}
$$

where $\gamma_{t}$ is the price associated with characteristics. As before, the average price and its standard error are obtained using the estimated time-series. Shanken (1992b) and Jagannathan and Wang (1998) show that, even though the firm characteristics are not estimated, the EIV in betas still necessitates a correction for the standard errors of $\gamma$ 's also. If the interest is only in checking the pricing of the characteristics and all the factors are traded portfolios, then one can reduce the EIV problem by moving the betas to the left-hand side of the equation. In other words, one imposes the null that the factor risk premium is equal to the factor mean and estimates the following equation:

$$
R_{t}-\widehat{B} F_{t}=\lambda_{0 t}+Z \gamma_{t}+\alpha_{t}
$$

Brennan et al. (1998) pioneer this approach in their analysis of pricing of characteristics in individual stocks. It is important to note that even this approach necessitates a correction of standard errors.

In practice, one almost always employs firm characteristics that vary over time. There are relatively few analytical results in the literature for the case dealing with time-varying characteristics. Jagannathan et al. (2010b) is one of the first attempts to deal with this problem. These authors show that if the expected returns are posited to depend on average characteristics, then using time-varying characteristics leads to biased and inconsistent estimators. They go on to provide analytical expressions for this bias. The question of whether there is a bias in the traditional Fama-MacBeth approach if expected returns vary with time-varying characteristics is still unexplored. 


\subsubsection{Large number of assets}

All the results so far (TSR, CSR, and Fama-MacBeth) are derived under the assumption that one has a small number of assets and the limiting distributions assume that $T \rightarrow \infty$. In other words, the estimators provided so far are $T$-consistent. With the advances in computing power, researchers are more frequently running regressions with a large number of assets. If one assumes $T$ to be fixed, classical analysis shows that EIV induces not only a problem of the standard error but also the coefficient estimates are biased and inconsistent. Shanken (1992b), building on the work of Litzenberger and Ramaswamy (1979), derives an estimator that is $N$-consistent. If the secondstage regression is run using an intercept, then the $N$-consistent estimator is given by

$$
\left(X^{\prime} X-\frac{\operatorname{tr}\left(\Sigma_{\varepsilon}\right)}{T-1} M^{\prime} \Sigma_{F}^{-1} M\right) X^{\prime} R_{t},
$$

where $X=\left[1_{N}: B\right]$, tr is the trace operator, and $M=\left[0: I_{K}\right]$. Kim (1995) uses maximum likelihood approach to improve upon this by providing an EIV-correction that is robust to conditional heteroskedasticity. Gagliardinia et al. (2011) explore the properties of these estimators under both $T$ and $N$ increasing.

\subsection{Stochastic discount factor methodology}

Most asset pricing models can be recast in stochastic discount factor (SDF) framework (Cochrane 2005). The SDF equation follows from the first-order condition of utility maximization by a representative investor and is usually written as

$$
E\left[m_{t} R_{t}\right]=0,
$$

where $R_{t}$ is the vector of excess returns and $m_{t}$ is the SDF and the equation is the unconditional version of the asset-pricing restriction. This equation is most naturally cast in GMM framework and readily admits non-linear $m_{t}$ 's. If one specifies the discount factor as $m_{t}=1-b^{\prime} F_{t}$, where $F_{t}$ is $K \times 1$ vector of factors, then the unknown parameters are $b$ 's. ${ }^{2}$ One can then use the GMM machinery to specify the moment conditions as

$$
\mathrm{E}\left[\left(1-b^{\prime} F_{t}\right) R_{t}\right]=0_{N \times 1} .
$$

The number of moment conditions is $N$ and the number of unknown parameters is $K$. The system is, thus, over-identified. Defining $d$ and $S$ matrices to be

$$
d=\mathrm{E}\left[R_{t} F_{t}\right]=\frac{1}{T} \sum_{t=1}^{T} R_{t} F_{t},
$$

and

$$
S=\sum_{j=-\infty}^{\infty} \mathrm{E}\left[\left(R_{t}-b^{\prime} F_{t} R_{t}\right)\left(R_{t}-b^{\prime} F_{t} R_{t}\right)^{\prime}\right]
$$

\footnotetext{
${ }^{2}$ I have implicitly normalized the intercept in the discount factor to be one.
} 
we can obtain the estimates of $b$ by using either an identity weighting matrix $\left(b_{1}\right)$ or the optimal $S^{-1}$ weighting matrix $\left(b_{2}\right)$ on the moments. The corresponding estimates and their variances are given by

$$
\begin{aligned}
& \widehat{b}_{1}=\left(d^{\prime} d\right)^{-1} d^{\prime} \bar{R}_{T}, \quad \operatorname{var}\left(\widehat{b}_{1}\right)=\frac{1}{T}\left(d^{\prime} d\right)^{-1} d^{\prime} S d\left(d^{\prime} d\right)^{-1}, \\
& \widehat{b}_{2}=\left(d^{\prime} S^{-1} d\right)^{-1} d^{\prime} S^{-1} \bar{R}_{T}, \quad \operatorname{var}\left(\widehat{b}_{2}\right)=\frac{1}{T}\left(d^{\prime} S d\right)^{-1} .
\end{aligned}
$$

The pricing errors are the moment conditions themselves. It is possible to derive the limiting distribution of the moment conditions. However, these involve generalized inverses. Hansen (1982) shows that the following $J$-statistic, which is distributed as $\chi_{N-K}^{2}$, can be used to check for over-identifying conditions as well as to check for the asset pricing condition of zero pricing errors (under the assumption that $\widehat{b}$ estimates are obtained from the efficient $S^{-1}$ weighting matrix):

$$
J=T \widehat{g}_{T}^{\prime} S^{-1} \widehat{g}_{T}, \quad \text { where } \widehat{g}_{T}=\frac{1}{T} \sum_{t=1}^{T}\left(1-\widehat{b}^{\prime} F_{t}\right) R_{t} .
$$

Whether to use the identity matrix or the $S^{-1}$ matrix for GMM depends on the objective of the researcher. An identity matrix gives equal weight to all the assets while the efficient weighting matrix gives more weight, in general, to assets with lower return variances. Cochrane (2005) emphasizes the usage of a weighting matrix that is economically interesting. There is a potential pitfall of using the $S^{-1}$ weighting matrix. Since this matrix changes with assets as well as model parameters, it is not possible to compare competing models. For instance, one model may do better simply because the $S$ matrix is large leading to bigger $J$-statistic. Hansen and Jagannathan (1997) suggest a solution to this problem by looking at the pricing errors of those portfolio whose second moments are normalized to one. In particular, they recommend using $W=E\left[R_{t} R_{t}^{\prime}\right]=(1 / T) \sum_{t} R_{t} R_{t}^{\prime}$ as the weighting matrix in the moment conditions and show that

$$
\mathrm{HJ}=\sqrt{\widehat{g}_{T}^{\prime} W^{-1} \widehat{g}_{T}}
$$

equals the least-square distance between the candidate SDF and the set of all valid SDFs ( $\widehat{g}_{T}$ in this equation in based on the estimates $\widehat{b}$ obtained using the $W$ weighting matrix). This statistic is commonly known as the Hansen-Jagannathan (HJ) distance.

SDF is an alternative to the TSR and CSR approaches for testing linear betapricing models. Jagannathan and Wang (2002) show that SDF and the traditional methods yield equally precise estimates of the risk premia and the two tests have equal power even for non-normal returns. Which method one uses is, therefore, largely a matter of individual preference.

\subsection{Time-varying betas and/or risk premium}

All the methods discussed so far assume time-invariant moments of returns and factors. Sometimes linear factor models include parameters that may vary over time and 
as functions of conditioning information. The distinction between unconditional and conditional models then becomes important for testing purposes. In general, unconditional versions of conditional models are not the same as unconditional models. For example, a typical conditional beta-pricing model would state the asset pricing restriction as

$$
\mathrm{E}_{t}\left(R_{t+1}\right)=B_{t} \lambda_{t},
$$

where $R$ is the vector of excess returns, $B_{t}$ are the conditional betas given by $B_{i t}=$ $\operatorname{cov}_{t}\left(R_{i t+1}, F_{t+1}\right) / \operatorname{var}_{t}\left(F_{t+1}\right)$, and $\lambda_{t}$ is the conditional factor premium. Taking the unconditional expectations on both sides, we get

$$
\mathrm{E}\left(R_{t+1}\right)=\mathrm{E}\left(B_{t}\right) \mathrm{E}\left(\lambda_{t}\right)+\operatorname{cov}\left(B_{t}, \lambda_{t}\right)
$$

which is not the same as the unconditional equation (1). This means that one may erroneously reject a conditional asset-pricing model if one tests its (incorrect) unconditional version. The only cases where it is okay to test an unconditional version are where either the betas or the risk premia are constants, ${ }^{3}$ or the conditional beta and the risk premia are uncorrelated.

It is not possible to estimate (45) without imposing further restrictions. In fact, Hansen and Richard (1987) show that one cannot test any conditional pricing model without access to all the conditioning information available to investors. The usual way out of this conundrum is to specify some instruments that the researcher feels are good candidates for characterizing the conditional distribution. We start by the most simple setup by assuming that the risk premia is constant. In this case, there is no difference between a conditional and an unconditional model. One can specify that the time-varying betas are linear functions of predetermined variables $Z$ (these variables may be stock-specific or macroeconomic) as $B_{t}=B_{0}+B_{1} Z_{t}$. One usually specifies intercepts also as functions of the same variables (Ferson and Harvey 1991, 1999). The TSR for traded factors can then be written as

$$
R_{t+1}=\left(\alpha_{0}+\alpha_{1} Z_{t}\right)+\left(B_{0}+B_{1} Z_{t}\right) F_{t+1}+\varepsilon_{t+1},
$$

with the asset pricing restriction $\alpha_{0}=\alpha_{1}=0$. Very similar setup can also be used in CSR which allows for additional characteristics to explain returns. Avramov and Chordia (2006) and Chordia et al. (2011) follow this approach to model betas as linear functions of firm characteristics.

A commonly used approach to allow for time-variation in betas and risk premiums is to model these separately as functions of predetermined variables. For instance, one can model expected asset returns, expected factor returns, and betas separately as functions of variables $Z$ and then use the moment conditions

$$
\mathrm{E}\left[\begin{array}{c}
R_{t}-h_{R}\left(Z_{t-1} ; \theta_{R}\right) \\
F_{t}-h_{F}\left(Z_{t-1} ; \theta_{F}\right) \\
h_{R}\left(Z_{t-1} ; \theta_{R}\right)-h_{B}\left(Z_{t-1} ; \theta_{B}\right) h_{F}\left(Z_{t-1} ; \theta_{F}\right)
\end{array}\right]=0_{2 N+K}
$$

\footnotetext{
${ }^{3}$ It is not enough that the conditional beta is constant. For example, it may be that both $\operatorname{cov}_{t}\left(R_{i t+1}, F_{t+1}\right)$ and $\operatorname{var}_{t}\left(F_{t+1}\right)$ are time-varying but that their ratio is constant. This would lead to a constant conditional beta but this would still be different from its unconditional counterpart, $\operatorname{cov}\left(R_{i t+1}, F_{t+1}\right) / \operatorname{var}\left(F_{t+1}\right)$.
} 
in a GMM framework. The unknown parameters are $\theta_{R}, \theta_{F}$, and $\theta_{B}$ and the functions $h\left(Z_{t} ; \cdot\right)$ may be non-linear in $Z_{t}$. For example, Ferson and Korajczyk (1995) assume that functions describing expected returns for returns and factors are linear. One problem with this method is the potential inconsistency in the specifications of $h_{R}, h_{F}$, and $h_{B}$. Ferson and Harvey (1993) reject that all three functions are linear. One may, therefore, omit one group of these moment conditions and test the remaining system.

Finally, one could employ the SDF methodology to model time-varying moments. For instance, the discount factor can be specified as $m_{t+1}=\left(a_{0}+a_{1} Z_{t}\right)+$ $b^{\prime}\left(F_{t+1} \otimes Z_{t}\right)$ and used as described in the previous subsection. The factors $F_{t+1} \otimes Z_{t}$ are referred to as scaled factors (Jagannathan and Wang 1996).

\section{Empirical evidence}

Tests of asset pricing models have, unsurprisingly, followed theoretical developments. I start with a review of the early tests of CAPM. A large part of my review is devoted to various empirical challenges to CAPM and its successors. I end with a discussion of the tests of models motivated by ICAPM/CCAPM.

\subsection{Early tests}

The results in very early tests in Lintner (1965b) and Douglas (1969) seem to reject the notion that expected returns are related only to market betas. However, Miller and Scholes (1972) and Black et al. (1972) in careful econometric analysis show that this conclusion is not warranted and highlight the problems in the measurement of beta. These researchers recommend grouping securities into betas, an approach that has since become standard. ${ }^{4}$ Fama and MacBeth (1973) sort securities into portfolios based on their historical betas to mitigate the loss of statistical power of grouping. They find evidence more consistent with CAPM; expected returns are related only to beta and not to residual risk, and the market risk premium is positive. ${ }^{5}$

Nevertheless, there are chinks in the CAPM armor in even these early tests. There was evidence that the zero-beta rate was higher than the risk-free rate, although this could be accounted for by Black's (1972) version of CAPM. A more serious problem was that these studies typically found that the relation between expected returns and market betas was too flat. In other words, Jensen's (1968) alpha was positive for assets with low betas and negative for assets with high betas.

Roll (1977) provides another critique of these tests by observing that the tests suffer from the non-observability of the true market portfolio. Thus, what is being tested

\footnotetext{
${ }^{4}$ Using portfolios instead of betas, however, leads to loss of information resulting in inefficient estimates. See Ang et al. (2010).

${ }^{5}$ The early literature also had to deal with estimation issues in beta. Dimson (1979) and Scholes and Williams (1977) show how to estimate betas in the presence of non-synchronous trading. Their procedures are modified by Fowler and Rorke (1983) and Cohen et al. (1983). Also see Asparouhova et al. (2010) for discussion of microstructure liquidity biases in estimation of betas. Finally, there is a vast literature starting from Rosenberg and Guy (1976) that uses firm and industry characteristics to obtain better estimates of beta.
} 
is at best the mean-variance efficiency of a proxy of the market portfolio. Roll's critique is potentially very damaging as it implies that there is very little hope of ever testing CAPM because it is not possible to construct the market portfolio of all assets. However, Stambaugh (1982) examines various proxies of the market portfolio (including stocks, bonds, real-estate, and consumer durables) and finds that inferences are not very sensitive to the market proxy. Kandel and Stambaugh (1987) and Shanken (1987) also show that if the correlation between the proxy and the true market return is higher than 0.7 , then rejections of CAPM with proxy also imply rejections of CAPM with true market return. It seems, therefore, that the unobservability of the market portfolio is not especially relevant in interpreting challenges to CAPM.

\subsection{Anomalies}

Several studies started to appear beginning with late 1970s that provided even less flattering image of CAPM. Most of the studies documenting anomalies follow a similar pattern. They posit that a variable, often based on stock characteristics, is related to the cross section of expected risk-adjusted returns. This is established via portfolio sorts (examining alphas from TSR) and/or Fama-MacBeth regressions (examining the premium on the variable of interest). To provide some structure on the plethora of studies, I broadly follow the taxonomy proposed by Subrahmanyam (2010) and separate these variables into two categories: (i) those based on informal reasoning, and (ii) those based on liquidity and other trading frictions. This list is not intended to be exhaustive or mutually exclusive.

\subsubsection{Anomalies based on informal reasoning}

Various firm characteristics have been found to explain returns. I classify them further into price-based, return-based, accounting-based, and idiosyncratic-risk based ratios.

Price-based ratios Basu (1977) and Ball (1978) find that firms with low priceearnings ratios have higher returns (higher than those predicted by CAPM) than those with high price-earnings ratios. In other words, the market portfolio is not efficient relative to portfolios of stocks formed by sorting on price-earnings ratios. ${ }^{6}$ Banz (1981) shows that small capitalization stocks have higher returns than large capitalization stocks. Miller and Scholes (1972) find that low priced stocks earn higher returns. These value- and size-effects are related as low price-earnings ratio firms also tend to be small/have low prices. Bhandari (1988) finds that firms with high leverage (measured by the ratio of book value of debt to market value of equity) earn abnormally high returns. On a similar vein, Stattman (1980) and Rosenberg et al. (1985) show that firms with high book-to-market $(\mathrm{B} / \mathrm{M})$ equity ratios have higher returns than those with low $\mathrm{B} / \mathrm{M}$ ratios. The common denominator in all these variables is the use of market price. The cross section of scaled market price, being related to

\footnotetext{
${ }^{6}$ The notion that 'cheap' stocks are a better deal has, in fact, an illustrious and long history on Wall Street, being espoused by Graham and Dodd (1934) and their famous disciple, Warren Buffett.
} 
Table 1 Size and book-to-market sorted portfolios. Stocks are sorted into portfolios in June of year $t$ and held from July $t$ to June $t+1$ (further details on portfolio construction are on Ken

French's website). The table reports average returns, standard deviation of returns, and CAPM alpha and market beta. All returns and alphas are in percent per month and the corresponding $t$-statistics are in parentheses. The sample includes all US stocks. The sample period is 1946 to 2010

\begin{tabular}{|c|c|c|c|c|}
\hline Decile & Mean & Std. dev. & Alpha & Beta \\
\hline \multicolumn{5}{|c|}{ Panel A: Size sorted portfolios } \\
\hline Small $=1$ & 1.16 & 6.15 & $0.15(1.10)$ & $1.12(35.30)$ \\
\hline 2 & 1.11 & 6.02 & $0.07(0.62)$ & $1.18(45.12)$ \\
\hline 3 & 1.16 & 5.74 & $0.12(1.25)$ & $1.18(53.52)$ \\
\hline 4 & 1.12 & 5.52 & $0.10(1.09)$ & $1.15(56.97)$ \\
\hline 5 & 1.13 & 5.33 & $0.12(1.57)$ & $1.13(65.16)$ \\
\hline 6 & 1.08 & 5.06 & $0.09(1.43)$ & $1.10(75.55)$ \\
\hline 7 & 1.09 & 4.97 & $0.09(1.76)$ & $1.10(90.98)$ \\
\hline 8 & 1.06 & 4.83 & $0.07(1.57)$ & $1.08(101.88)$ \\
\hline 9 & 1.01 & 4.47 & $0.07(1.84)$ & $1.01(121.76)$ \\
\hline $\mathrm{Big}=10$ & 0.89 & 4.14 & $-0.01(-0.31)$ & $0.94(122.71)$ \\
\hline Small-big & 0.27 & 4.60 & $0.16(1.00)$ & $0.18(4.84)$ \\
\hline
\end{tabular}

Panel B: Book-to-market sorted portfolios

\begin{tabular}{lcccc}
\hline Growth $=1$ & 0.87 & 4.95 & $-0.11(-1.70)$ & $1.07(71.68)$ \\
2 & 0.93 & 4.54 & $-0.01(-0.19)$ & $1.00(90.58)$ \\
3 & 0.95 & 4.47 & $0.03(0.51)$ & $0.98(82.97)$ \\
4 & 0.94 & 4.54 & $0.01(0.20)$ & $0.98(72.64)$ \\
5 & 1.05 & 4.25 & $0.17(2.68)$ & $0.90(61.70)$ \\
6 & 1.05 & 4.38 & $0.15(2.45)$ & $0.94(68.11)$ \\
7 & 1.03 & 4.37 & $0.16(2.16)$ & $0.89(53.54)$ \\
8 & 1.19 & 4.57 & $0.29(3.68)$ & $0.93(51.20)$ \\
9 & 1.20 & 4.76 & $0.28(3.32)$ & $0.96(49.21)$ \\
Value $=10$ & 1.30 & 5.83 & $0.30(2.49)$ & $1.11(40.13)$ \\
Value-growth & 0.43 & 4.49 & $0.41(2.53)$ & $0.04(1.00)$ \\
\hline
\end{tabular}

the expectations of future cash flows and discount rates, thus reveals differences in expected returns. In principle, risk/beta from asset pricing models such as CAPM should pick up these cross-sectional differences. The fact that it does not thus reveals the shortcomings of CAPM.

Fama and French (1992) synthesize this evidence. They show that the relation between betas and expected returns is even flatter than that documented by earlier studies; the market risk premium is economically small and statistically insignificant leading some to dub this as the 'death of beta.' This influential study also shows that, while the price-based variables cited before are useful for explaining returns, two variables that stand out in multivariate cross-sectional regressions are size and bookto-market. Fama and French (1996) reach similar conclusions using TSR approach on portfolios sorted by price ratios.

Table 1 gives an update on these results. The table shows market betas and alphas for portfolios sorted on market capitalization (Panel A) and book-to-market ratios (Panel B) for the sample of US stocks over the sample period of 1946 to 2010 (the data are downloaded from Ken French's website at http://mba.tuck.dartmouth.edu/pages/ faculty/ken.french/data_library.html). Small stock returns are $0.27 \%$ higher, on av- 
erage, than those of large stocks. The CAPM alpha of the long-short small-big portfolio is $0.16 \%$, although statistically insignificant. In contrast, the value premium is stronger. Value stocks (stocks with high book-to-market) outperform growth stocks (stocks with low book-to-market) by $0.43 \%$ on average (CAPM alpha is $0.41 \%$ and statistically significant). It is important to note that these are violations of CAPM based on deviations from systematic risk/beta. Small (value) stocks have more volatile returns than large (growth) stocks. However, the difference in betas between these categories of stocks is not enough to explain the differences in average returns.

Return-based ratios Fama and French (1988) report negative serial correlation in market returns over intervals of three to five years and Lo and MacKinlay (1988) show positive correlation in weekly returns for disaggregated portfolios. The results in these early studies, while sometimes statistically significant, do not indicate whether the predictability is economically significant. Jegadeesh (1990) had the important insight of exploiting this predictability by looking at portfolio returns. He shows that there is economically significant reversal; winner stocks have lower nextmonth returns than do loser stocks, where winner and loser stocks are based on prior month returns. Lehmann (1990) shows similar patterns at weekly horizons. Cooper (1999) argues that these patterns are a result of overreaction while Avramov et al. (2006) show the role of illiquidity in explaining these reversals.

Jegadeesh and Titman $(1993,2001)$ demonstrate an even more robust and stronger pattern of return-based strategies. They show that returns based on past 12 to 2 months have strong predictive power for future returns over horizons of up to one year. Grinblatt and Moskowitz (1999) explore whether industry effects explain this phenomenon while Chordia and Shivakumar (2002) argue that momentum profits can be explained by business cycles. Liu and Zhang (2008) argue that a factor based on growth rate of industrial production explains more than half the momentum profits. The momentum effect is also robust in international markets, as documented by Rouwenhorst (1998), Griffin et al. (2003), and Chui et al. (2010). Fama and French (2011) show that momentum profits, while pervasive in international markets (with the notable exception of Japan), are stronger in small stocks than in big stocks. Heston and Sadka (2008), building on regression results of Jegadeesh (1990), show that winners in a given month outperform losers in the same month for up to 20 annual lags. Asness et al. (2009) and Moskowitz et al. (2010) show that momentum is present not only in international equity markets but also in other asset classes such as government and corporate bonds, currencies, and commodities.

There are also several studies that refine the basic momentum strategy. For instance, Hong et al. (2000) show that momentum profits are stronger in small stocks and stocks with low analyst coverage. Doukas and McKnight (2005) replicate these results for European markets. Cooper et al. (2004) show that momentum profits are higher after positive market returns than after negative ones. Avramov et al. (2007) document that bulk of momentum profits are concentrated in low credit quality firms. Hvidkjaer (2006) shows that momentum strategy is related to order flows. In an intriguing result, Novy-Marx (2010) finds that momentum is stronger for sorting stocks on intermediate returns ( 7 to 12 months prior to portfolio formation) than that on re- 
cent returns ( 2 to 6 months prior to portfolio formation). However, Goyal and Wahal (2011) show that this 'echo' is not present in international markets.

There is also evidence of long-term reversal. De Bondt and Thaler $(1985,1987)$ show that winners underperform losers over three- to five-year horizons. These results clearly show the economic importance of the negative long-horizon return autocorrelations documented by Fama and French (1988). Conrad and Kaul (1993) argue that this long-horizon reversal is mainly in low-priced stocks and, therefore, not pervasive. Loughran and Ritter (1996) counter by raising methodological issues with Conrad and Kaul study and by arguing that low prices simply proxy for low past returns.

The anomalies based on returns pose a significant challenge not only to CAPM but to the efficient markets hypothesis, originally proposed by Fama (1970). Since they require knowledge of only past prices, they violate even the weak-form of market efficiency. Table 2 shows the results of short-term reversal, medium-term momentum, and long-term reversal portfolios using US stocks over 1946 to 2010. In addition to CAPM alphas, I also show Fama and French's (1993) three-factor alphas (this model is discussed later in Sect. 3.2.3). The difference in returns between winners and losers is $-0.53,1.32$, and $-0.34 \%$ for stocks sorted on past month, past 2 to 12 months, and past 13 to 60 months returns, respectively. These differences in returns are, in general, not explained by risk factors. One-factor alphas are similar in magnitude to excess returns. Three-factor alphas show modest mispricing for short-term reversal but subsume completely the long-term reversal. In contrast, three-factor alphas for medium-term momentum portfolios are even larger than one-factor alphas. The magnitude of alphas for the long-short winners-losers portfolio is astounding $1.64 \%$. Fama (1998) and Fama and French (2008) concede momentum as posing the biggest challenge to efficient markets hypothesis.

Accounting-based ratios There is also a vast literature that uses primarily accounting-based information to predict the cross section of returns. Lakonishok et al. (1994) find a negative relation between returns over long horizon and financial performance such as earnings and sales growth. La Porta (1996) shows that analysts' long-run earnings growth forecasts are negatively related to future returns. Haugen and Baker (1996) and Cohen et al. (2002) find that more profitable firms have higher returns than less profitable firms.

There have also been studies of the relation between investments and stock returns with mixed results. Chan et al. (2001) report that there is no difference in returns between firms doing $R \& D$ and those doing no R\&D. However, amongst the firms engaged in $R \& D$, high $R \& D$ expenditure relative to market value of equity signals high future excess returns. Titman et al. (2004), however, find that firms that invest more have lower stock returns. Cooper et al. (2008) report that firms with high asset growth have low returns; Lipson et al. (2010) show that this anomaly is stronger with in stocks with higher idiosyncratic volatility. Titman et al. (2010) and Watanabe et al. (2011) show that asset-growth anomaly exists in international markets too.

Sloan (1996) shows that accounting accruals are negatively related to returns suggesting that investors are unable to distinguish between accounting income and cash flows. Frankel and Lee (1998) show that residual-income based valuation models 
Table 2 Past return sorted portfolios. Stocks are sorted monthly into portfolios based on prior returns (further details on portfolio construction are on Ken French's website). The table reports average returns, standard deviation of returns, and CAPM and Fama and French (1993) three-factor alphas. All returns and alphas are in percent per month and the corresponding $t$-statistics are in parentheses. The sample includes all US stocks. The sample period is 1946 to 2010

\begin{tabular}{|c|c|c|c|c|}
\hline Decile & Mean & Std. dev. & Alpha $_{1}$ & $\mathrm{Alpha}_{3}$ \\
\hline \multicolumn{5}{|c|}{ Panel A: Prior $[-10]$ return sorted portfolios } \\
\hline Losers $=1$ & 1.08 & 6.79 & $-0.07(-0.64)$ & $-0.09(-0.85)$ \\
\hline 2 & 1.20 & 5.45 & $0.18(2.20)$ & $0.13(1.64)$ \\
\hline 3 & 1.19 & 4.86 & $0.23(3.42)$ & $0.19(2.84)$ \\
\hline 4 & 1.06 & 4.52 & $0.13(2.32)$ & $0.08(1.53)$ \\
\hline 5 & 1.00 & 4.37 & $0.09(1.73)$ & $0.06(1.14)$ \\
\hline 6 & 0.94 & 4.22 & $0.04(0.84)$ & $0.02(0.48)$ \\
\hline 7 & 0.91 & 4.20 & $0.02(0.43)$ & $-0.02(-0.37)$ \\
\hline 8 & 0.91 & 4.37 & $0.00(0.03)$ & $-0.00(-0.06)$ \\
\hline 9 & 0.74 & 4.62 & $-0.19(-2.83)$ & $-0.18(-2.66)$ \\
\hline Winners $=10$ & 0.55 & 5.32 & $-0.43(-4.58)$ & $-0.41(-4.55)$ \\
\hline Losers-winners & 0.53 & 4.85 & $0.35(2.09)$ & $0.32(1.88)$ \\
\hline \multicolumn{5}{|c|}{ Panel B: Prior $[-12-2]$ return sorted portfolios } \\
\hline Losers $=1$ & 0.24 & 7.46 & $-0.92(-5.74)$ & $-1.03(-6.60)$ \\
\hline 2 & 0.66 & 5.84 & $-0.37(-3.34)$ & $-0.48(-4.34)$ \\
\hline 3 & 0.81 & 5.03 & $-0.13(-1.36)$ & $-0.23(-2.48)$ \\
\hline 4 & 0.86 & 4.59 & $-0.05(-0.69)$ & $-0.14(-2.01)$ \\
\hline 5 & 0.88 & 4.29 & $-0.01(-0.15)$ & $-0.10(-1.68)$ \\
\hline 6 & 0.93 & 4.36 & $0.02(0.39)$ & $-0.04(-0.79)$ \\
\hline 7 & 0.99 & 4.31 & $0.10(1.57)$ & $0.05(0.83)$ \\
\hline 8 & 1.15 & 4.43 & $0.25(4.00)$ & $0.21(3.47)$ \\
\hline 9 & 1.18 & 4.75 & $0.24(3.48)$ & $0.23(3.30)$ \\
\hline Winners $=10$ & 1.56 & 5.94 & $0.52(4.73)$ & $0.62(5.94)$ \\
\hline Winners-losers & 1.32 & 6.41 & $1.44(6.29)$ & $1.64(7.16)$ \\
\hline \multicolumn{5}{|c|}{ Panel C: Prior [ $-60-13]$ return sorted portfolios } \\
\hline Losers $=1$ & 1.23 & 6.14 & $0.21(1.59)$ & $-0.06(-0.62)$ \\
\hline 2 & 1.11 & 4.87 & $0.18(2.07)$ & $-0.00(-0.02)$ \\
\hline 3 & 1.13 & 4.52 & $0.24(3.09)$ & $0.09(1.22)$ \\
\hline 4 & 1.00 & 4.30 & $0.12(1.81)$ & $-0.03(-0.43)$ \\
\hline 5 & 1.02 & 4.28 & $0.13(2.14)$ & $0.02(0.34)$ \\
\hline 6 & 1.02 & 4.22 & $0.14(2.26)$ & $0.05(0.91)$ \\
\hline 7 & 1.02 & 4.36 & $0.13(2.09)$ & $0.08(1.36)$ \\
\hline 8 & 0.96 & 4.45 & $0.05(0.74)$ & $0.03(0.52)$ \\
\hline 9 & 0.88 & 4.77 & $-0.07(-1.14)$ & $-0.05(-0.78)$ \\
\hline Winners $=10$ & 0.89 & 5.81 & $-0.19(-2.57)$ & $-0.04(-0.60)$ \\
\hline Losers-winners & 0.34 & 4.71 & $0.40(2.38)$ & $-0.02(-0.16)$ \\
\hline
\end{tabular}

generate a value-price ratio that has predictive power for future returns. Lee et al. (1999) use this valuation model to calculate the intrinsic value of Dow 30 stocks.

There is also a relation between firm financing decisions and stock returns. Loughran and Ritter (1995) show that stock returns are negative after equity issuances 
and Ikenberry et al. (1995) show that repurchases generally result in positive stock returns. Daniel and Titman (2006) and Pontiff and Woodgate (2008) combine these pieces of evidence to show a negative relation between net stock issues and future stock returns.

Finally, there is very old literature going back to Ball and Brown (1968) who show that stock prices continue to drift in the direction of earnings surprises for several months after the earnings are announced. Bernard and Thomas (1989, 1990) show that this anomaly is still robust after its initial discovery, although Chordia et al. (2009) show that this anomaly is prevalent in only illiquid stocks. Womack (1996) shows that stock prices also drift in the direction of analysts' revisions and Sorescu and Subrahmanyam (2006) show that the drift occurs only for experienced analysts.

Idiosyncratic-risk based ratios A central tenet of asset pricing models is that only systematic risk gets compensated. Nevertheless, there are several asset pricing models that take idiosyncratic risk into account. Levy (1978), Merton (1987), and Malkiel and $\mathrm{Xu}$ (2002) build extensions of the CAPM where investors, for some exogenous reason, hold undiversified portfolios.

Early research, for example Fama and MacBeth (1973), finds no support for pricing of idiosyncratic risk. However, Lehmann (1990) reaffirms the results of Douglas (1969) after conducting a careful econometric analysis. Malkiel and Xu (1997, 2002) also present evidence of the importance of idiosyncratic risk in explaining the cross section of expected stock returns, even after controlling for size. In more recent work, Ang et al. (2006, 2009) present evidence that stock returns are negatively related to idiosyncratic risk. Their study is interesting because not only it shows a relation between idiosyncratic risk and return but also the relation goes the other way than that would be suggested by basic risk-return trade-off.

However, this study has been controversial. Bali and Cakici (2008) find that minor variations in research design invalidate the main findings. Huang et al. (2010) show that return reversals over one month are the major reason for the negative relation between idiosyncratic volatility and returns. In a twist, Fu (2009) shows that alternative volatility calculations lead to a positive relation between idiosyncratic volatility and returns. Finally, in a comprehensive analysis, Fink et al. (2011) show that there is indeed a positive relation between idiosyncratic volatility and returns but only if the investors know all the parameters of the model used to calculate idiosyncratic volatility. They also show that there is no relation between idiosyncratic volatility forecasts made using real-time data and future returns, invalidating the use of this anomaly for a trading strategy.

\subsubsection{Anomalies based on liquidity and trading frictions}

Most of the asset pricing models assume frictionless markets. Trading costs are, however, of course, an integral part of the investment process. The literature on incorporating trading frictions in theoretical models as well as empirical studies was slow to pick up. The recent financial crisis has highlighted the importance of liquidity in the functioning of capital markets. This has given a huge impetus and liquidity has become an area of active research. 
Liquidity as a characteristic The returns realized by investors are net of trading costs. This implies that stocks with higher trading costs should command higher returns to compensate for their lack of liquidity. Amihud and Mendelson (1986) pioneer this concept of liquidity being priced in stock prices. They document that there is a premium for bid-ask spread in stock returns. Liquidity is, however, multifaceted and different authors use different measures of liquidity. Datar et al. (1998) and Brennan et al. (1998) find that turnover as a proxy for liquidity is negatively related to future stock returns. Brennan et al. (2010) find that the effect of illiquidity is primarily from the sell-side. One of the most commonly used indicators of (il)liquidity is the one proposed by Amihud (2002) and is measured as the ratio of absolute return to dollar trading volume. Hasbrouck (2009) presents evidence of pricing of various, but not all, liquidity measures.

Liquidity as risk A parallel literature studies whether liquidity is a priced risk factor. Acharya and Pedersen (2005) provide a useful taxonomy of various components of liquidity risk. First, there maybe commonality in liquidity, the covariance between individual stock liquidity and market liquidity. Chordia et al. (2000), Hasbrouck and Seppi (2001), and Huberman and Halka (2001) document the existence of commonality in liquidity in the US stock market. Second, risk might arise due to the covariance between individual stock return and market liquidity. Pástor and Stambaugh (2003) measure illiquidity by the extent to which returns reverse high volume to capture this notion of liquidity and find that exposure to this liquidity risk is related to expected returns. Third, the covariance between individual stock liquidity and market return also leads to liquidity premium. Brunnermeier and Pedersen (2009) propose a theoretical model to consider the relationship between asset liquidity and funding availability in the stock market. Korajczyk and Sadka (2008) examine various liquidity measures and find that common component of these measures is a priced factor. At the same time, liquidity is also priced as a characteristic.

Information risk There is also a literature on the pricing of information risk. Easley and O'Hara (1987) develop a model where the probability of informed trading (PIN) is related to trading costs and stock returns. Easley et al. (1996), Easley et al. (2002), and Easley and O'Hara (2004) find support for the pricing of PIN in the cross section of stock returns. However, Duarte and Young (2009) report that it is only the liquidity trading component of PIN, rather than the information-based component, that is priced. Hou and Moskowitz (2005) find that one minus the $R^{2}$ from a market model regression is related to the cross section of stock returns. These authors interpret their measure capturing information asymmetry.

Short selling Miller (1977) proposes that stocks with short-sale constraints that will be overvalued as investors with negative outlook have a lower bound of zero on the number of shares that they can own. Jones and Lamont (2002) show that short-stockrebate rate is a good proxy for short sale constraints and stocks with this high cost of borrowing have low future returns. Desai et al. (2002) find statistically significant subsequent underperformance for heavily shorted firms. Asquith et al. (2005) show that stocks with high short interest and low institutional ownership (the authors argue 
that both these need to be present for a stock to be short sale constrained) earn low returns.

Diether et al. (2002) find that returns of stocks with higher dispersion of analysts' earnings forecasts are lower; the effect is more pronounced for small firms, high book-to-market firms, and low momentum firms. The authors interpret their finding to be consistent with Miller. However, Boehme et al. (2006) argue that both difference in opinion and short-sale constraints are necessary preconditions of Miller's model. The authors report evidence of significant overvaluation for stocks that are subject to both conditions simultaneously.

On a related topic, some studies examine the role of stock ownership in explaining the cross section of returns. Chen et al. (2002) show that stocks with an increase in breadth of ownership have higher returns than those with a decrease in breadth of ownership. This is consistent with the view that short sales are less binding when there are more investors with long positions. Nagel (2005) shows that stocks with high degree of institutional ownership have less cross-sectional predictability and exhibit more efficient pricing.

\subsubsection{Factor models inspired by anomalies}

I have already discussed liquidity-based factor models in Sect. 3.2.2. In this section, I review the most famous three-factor model of Fama and French (1993) and its fourfactor successor.

Three-factor model The interpretation of Fama and French (1992) study has been the subject of considerable controversy. The first possibility is that the results are spurious and due to data mining. However, Chan et al. (1991) show the B/M effect in Japan; Capaul et al. (1993) show a similar effect in four European markets and Japan; Fama and French (1998) document evidence of price-ratio based returns for twelve non-US major markets and emerging markets. More recently, Hou et al. (2011) and Fama and French (2011) provided more comprehensive and up-to-date evidence of size- and value-effects in international markets. Davis et al. (2000) provide an outof-sample study for the US market itself by extending the sample period back to 1927. These studies suggest that price-ratio based anomalies are not specific to the US and/or a sample period.

Another explanation for the price-ratio based anomalies is rooted in behavioral theories. Lakonishok et al. (1994) argue that investors overreact. Since stocks with high $\mathrm{B} / \mathrm{M}$ ratios are typically those that have fallen on hard times, investors irrationally extrapolate this performance resulting in too low prices for these stocks and too high prices for low $\mathrm{B} / \mathrm{M}$ stocks. The future pattern of returns is just a correction for this overreaction.

Fama and French (1993) propose a three-factor model to rationalize these anomalies. They show that two new factors (SMB and HML) in addition to the usual market factor are useful for explaining the cross section of returns. The SMB factor is meant to capture the covariation of returns with size while the HML factor captures the covariation of returns with book-to-market. Figure 1 plots the relation between actual returns and those predicted by CAPM (Panel A) and the three-factor model (Panel B) 
Fig. 1 CAPM versus Fama and French (1993). Stocks are sorted into portfolios in June of year $t$ and held from July $t$ to June $t+1$ (further details on portfolio construction are on Ken French's website). The figure plots the average actual returns versus returns predicted by CAPM and Fama and French (1993) model for 25 size and book-to-market double-sorted portfolios. The sample includes all US stocks. The sample period is 1946 to 2010
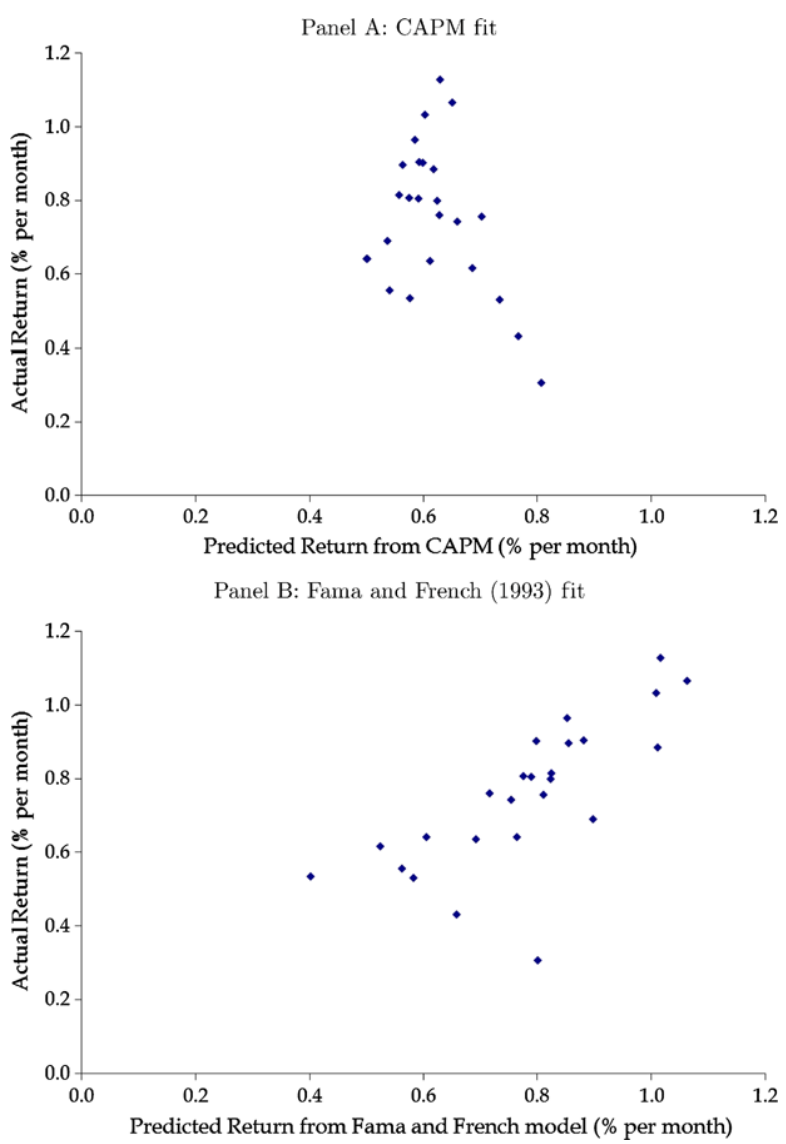

for 25 size- and book-to-market double-sorted portfolios. This security market line should have a slope of one and an intercept of zero if the asset pricing model is true. It is quite evident that the three-factor model does a better job of explaining the returns than does CAPM. At the same time, even the three-factor model leaves unexplained variation. The alphas of corner portfolios, particularly those of small-growth stocks, are large. In fact, the formal GRS statistic rejects even the Fama and French model.

The three factors in the Fama and French (1993) model are, moreover, not theoretically motivated. Even though Fama and French suggest that the value factor might be related to firms facing financial distress, Dichev (1998) reports that, on the contrary, distressed firms earn low returns. These findings have been corroborated by other studies such as Griffin and Lemmon (2002) and Campbell et al. (2008). ${ }^{7}$ Piotroski (2000) shows that amongst high B/M firms, firms with better fundamentals outperform the rest. This evidence seems contrary to the notion of HML as a distress factor and is more supportive of either underreaction to information, limits to arbitrage, or

\footnotetext{
${ }^{7}$ Kapadia (2011) constructs an aggregate distress risk factor based on business failures and finds that this portfolio hedges distress risk and exposures to this factor explain size-effect and value premium.
} 
inability to properly account for the option value of distressed firms (Eisdorfer et al. 2011).

There is also a debate in the literature about whether value stocks do better than growth stocks because of their exposure to risk factors or because of the mere fact that they are value stocks. Daniel and Titman (1997) argue that it is not the loadings on the factors but the characteristics themselves that explain the cross section of returns. This is debated by Davis et al. (2000). More recently, Chordia et al. (2011) showed that both betas and characteristics matter for explaining the returns; the relative contribution to explaining the cross-sectional variation of returns depends on which factors and/or characteristics one uses.

The empirical shortcomings aside, Fama and French's (1993) three-factor model remains extremely influential because it clarifies stylized and robust facts and, as cogently argued by Cochrane (2005), is more persuasive than simply a table of $\chi^{2}$ pricing errors. It has inspired a huge amount of theoretical research devoted to understanding why value stocks might do better than growth stocks. For example, Zhang (2005) argues that it is more costly for value firms to downsize their capital stocks since they are typically burdened with more unproductive capital. As a result, their returns covary more with economic downturns when the expected risk premium is high. I discuss some other models to explain these anomalies later in Sect. 3.3.

Four-factor model The three-factor model is unable to account for all the anomalies. The foremost amongst the unaccounted for anomalies is the momentum anomaly. As shown in Table 2, momentum strategies generate large and significant alphas even after accounting for three-factor risk correction. Carhart (1997), in a pioneering study of mutual fund performance, finds that much of the continuation in performance of past winner funds is accounted for by a momentum factor. Inspired by this evidence, performance measurement of delegated fund managers is now routinely carried out using a four-factor model. The four factors are the three Fama and French (1993) factors augmented with a momentum factor (UMD). Whether UMD is a reward for risk is, however, controversial. Much of the performance measurement literature does not take a stand on this issue and interprets UMD as a diversified passive benchmark return that capture patterns in average returns.

\subsection{Macroeconomic/consumption based factor models}

As mentioned earlier, the empirical failure of CAPM may be due to improper usage of the market portfolio (Roll 1977). Jagannathan and Wang (1996) and Campbell (1996) argue that human capital is an important part of the 'market' portfolio and that its inclusion improves CAPM's pricing performance.

It has generally been more fruitful, however, to test implication of Merton's (1973) ICAPM rather than the static CAPM. Campbell and Vuolteenaho (2004) demonstrate that beta can be decomposed into two parts; covariance of stock returns with market cash flows and with market discount rates. They find that their two-beta model is able to explain the value premium. Campbell et al. (2010) further decompose beta into four components related to covariance of a stock's cash flows and discount rate with those of the market. Their interest is in understanding common movements in 
stock prices and they report that the systematic risks of individual stocks are primarily driven by the systematic risks of their fundamentals. Brennan et al. (2004) show that stochastic real interest rate and maximum Sharpe ratio are state variables that help in explaining the returns on size- and B/M-sorted portfolios even better than the Fama and French (1993) model. Da (2009) shows that a model with consumption beta and duration of cash flows is useful in explaining these portfolio returns.

Several researchers have also used the intuition of Ross' (1976) APT to test for pricing of macroeconomic factors. APT factors are motivated by statistical considerations of describing the covariance matrix of returns while ICAPM factors are motivated by economic considerations of finding state variables that describe the evolution of investment opportunity set. In actual empirical practice, however, the distinction between APT and ICAPM is not always clear. Researchers routinely use macroeconomic factors, which presumably proxy for state variables, as tests of APT. Similarly, they routinely use factor portfolio returns, which presumably describe the common movements of returns, as tests of ICAPM.

Chen et al. (1986) find that macro factors are useful for pricing size-sorted portfolios. Their finding is, however, debated by Shanken and Weinstein (2006). Liew and Vassalou (2000) show that HML and SMB are related to future GDP growth implying that these portfolios act as state variables that describe the future state of the economy. Vassalou (2003) shows that a model with a factor related to news about to future GDP growth along with the market factor can price equities as well as the three-actor model. Petkova (2006) shows that factors related to innovations in macro variables such as term spread and default spread are priced and dominate the Fama and French (1993) factors.

Another strand of literature uses the intuition from real options to view firms as collection of assets in place and growth options. Berk et al. (1999) present a model where CAPM holds yet the expected returns on equities do not satisfy the CAPM pricing relation. Gomes et al. (2003), Carlson et al. (2004), Cooper (2006), and Zhang (2005) build on these insights to show the departures from CAPM can be rationalized in a world with investment costs and/or irreversibility of investments. Bernardo et al. (2007) and Da et al. (2011) highlight the importance of growth options of a firm for cost-of-capital calculations.

There is also a growing literature that uses $q$-theory to explain the cross-sectional pattern in returns. The literature was given impetus by the fundamental insight of Cochrane (1991) that consumption-based and production-based asset pricing are two sides of the same coin. Cochrane (1996) finds support for a production-based asset pricing model. Recent work relies on extensions of his basic model. For example, Anderson and Garcia-Feijoo (2006) and Xing (2008) find that the value effect disappears after controlling for proxies of firms' investment. In a series of papers, Li et al. (2009), Liu et al. (2009), Livdan et al. (2009), and Li and Zhang (2010) argue that most of the anomalies are explicable by extensions of $q$-theory to account for investment frictions.

Turning towards the more traditional consumption-based models, the central intuition is that the marginal utility of consumption is the SDF that prices all the assets. In other words, asset returns are compensation for their covariance with the marginal utility of consumption. Under some assumptions (for example, time-separable power 
utility) the marginal utility of consumption can be linearized to be the growth rate in aggregate consumption. Early tests in Breeden et al. (1989) find weak support for CCAPM. ${ }^{8}$ Part of the difficulty lies in measuring consumption growth. Jagannathan and Wang (2007) argue that year-to-year fourth-quarter consumption growth works better than quarterly consumption growth in pricing assets. Savov (2011) shows that growth in garbage is a better proxy for actual consumption growth than the usual measures.

Another avenue that has proved fruitful is to add labor income and/or wealth to usual CCAPM tests. Santos and Veronesi (2006) show that labor income to consumption ratio as a conditioning variable is useful for testing conditional version of CCAPM. Jacobs and Wang (2004) also show that idiosyncratic consumption risk is a priced factor. Lettau and Ludvigson (2001a, 2001b) argue that the co-integration ratio of consumption, wealth, and income (cay) is a priced risk factor and improves the cross-sectional pricing performance over both standard consumption-based models and Fama and French (1993) model. Nonseparable utility has also been found to be useful in explaining stock returns (Yogo 2006).

A more recent line of attack to resurrecting CCAPM comes from the observation that consumption risk should be measured by covariance of returns and consumption over several quarters (Parker and Julliard 2005). An influential paper by Bansal and Yaron (2004) proposes the so-called long-run risk model in which small but persistent innovations to consumption growth and its volatility can overcome several shortcomings of the basic CCAPM. Bansal et al. (2005, 2009), Hansen et al. (2008), and Malloy et al. (2009) find support for this model. However, Beeler and Campbell (2011) and Constantinides and Ghosh (2011) take issues with some of the implications of these models.

It is important to note that the efficacy of macroeconomic or consumption-based models is still judged by their ability to explain the anomalies of Sect. 3.2. Size-, value-, and momentum-effects remain the litmus tests for all asset pricing models. Therefore, the usual practice in empirical research is to still check for pricing errors of these portfolios from alternative factor models and test them against the CAPM and Fama and French (1993) factors.

\section{Conclusion}

I have reviewed the most common methodological approaches and the empirical evidence on cross-sectional asset pricing. Many challenges to CAPM are explained by the Fama and French (1993) model. Their model seems to have taken over the mantle of the model to beat. In the years since their seminal study, many new models have been proposed that challenge the pricing power of their three factors for the size- and

\footnotetext{
${ }^{8}$ The failure of CCAPM to explain the cross section of returns is related to the equity premium puzzle. Mehra and Prescott (1985) show that low volatility of consumption growth and its relatively low correlation with aggregate stock returns leads to an implausibly high risk reversion to justify the observed equity premium. This observation has led to tremendous amount of research that is too big to be even begun to be cited here. The interested reader is referred to Mehra (2008) for a recent synthesis of articles on this topic.
} 
book-to-market portfolios. New anomalies must be posed as something not explained by their three-factors, not merely by the CAPM market factor.

Empirical and methodological issues remain. First, it is not always clear if the anomalies are pervasive or concentrated in a particular group (say, small) stocks. Sometimes, but nor always, the researchers report results for size-sorted portfolios and/or controls for loadings on the size-factor. Both of these approaches are subject to problems highlighted by Fama and French (2008). Namely, portfolio sorts can be dominated by micro-cap stocks for equal-weighting or a few big stocks for valueweighting. Regressions are not much more help as the usual OLS approaches may end up giving more weight to small stocks. Fama and French's concerns are not specific to portfolio sorts and/or regressions and apply equally to GMM/SDF based tests. Fama and French, therefore, call for reporting separate results for different size groups to gauge the pervasiveness of results. Second, most of the literature also uses size- and $\mathrm{B} / \mathrm{M}$-sorted portfolios for testing asset pricing models. While there is no gainsaying the importance of looking at these portfolios, Lewellen et al. (2010) suggest looking at the pricing of different portfolios, namely industry portfolios, too.

Another concern is that these days one has a multitude of variables that seem to explain the cross-sectional pattern of returns. The amount of independent information in these variables is unclear as no study to date, to the best of my knowledge, has conducted a comprehensive study to analyze the joint impact of these variables. Such a study is, admittedly, not going to be easy. For instance, it is infeasible to sort stocks into portfolios based on more than three to four sorting variables. Multivariate regressions seem to be the only promising way forward. This poses its own problems, especially when dealing with large cross section of individual stocks. Finally, as Cochrane (2011) argues, one will have to dissect the pricing performance into that coming from covariances (the asset-pricing part) and that coming from characteristics (the remainder).

Stay tuned for exciting time ahead!

Acknowledgements I thank Manuel Ammann for helpful comments and Rajna Gibson for her support through her NCCR-FINRISK project. I apologize to all the authors whose papers I forgot to cite; omissions are not willful. I retain full credit for any misrepresentation of the authors' results cited in this paper, as well as all the errors.

\section{References}

Acharya, V.V., Pedersen, L.H.: Asset pricing with liquidity risk. J. Financ. Econ. 77(2), 375-410 (2005)

Amihud, Y.: Illiquidity and stock returns: cross-section and time-series effects. J. Financ. Mark. 5(1), 31$56(2002)$

Amihud, Y., Mendelson, H.: Asset pricing and the bid-ask spread. J. Financ. Econ. 17(2), 223-249 (1986)

Anderson, C.W., Garcia-Feijoo, L.: Empirical evidence on capital investment, growth options, and security returns. J. Finance 61(1), 171-194 (2006)

Anderson, T.W.: An Introduction to Multivariate Statistical Analysis, 3rd edn. Wiley-Interscience, New York (2003)

Ang, A., Liu, J., Schwarz, K.: Using stocks or portfolios in tests of factor models. Working paper (2010). http://ssrn.com/abstract=1106463

Ang, A., Hodrick, R.J., Xing, Y., Zhang, X.: The cross-section of volatility and expected returns. J. Finance 61(1), 259-299 (2006) 
Ang, A., Hodrick, R.J., Xing, Y., Zhang, X.: High idiosyncratic volatility and low returns: international and further US evidence. J. Financ. Econ. 91(1), 1-23 (2009)

Asparouhova, E., Bessembinder, H., Kalcheva, I.: Liquidity biases in asset pricing tests. J. Financ. Econ. 96(2), 215-237 (2010)

Asquith, P., Pathak, P., Ritter, J.: Short interest, institutional ownership, and stock returns. J. Financ. Econ. 78(2), 243-276 (2005)

Asness, C.S., Moskowitz, T.J., Pedersen, L.H.: Value and momentum everywhere. Working paper (2009). http://ssrn.com/abstract $=1363476$

Avramov, D., Chordia, T.: Asset pricing models and financial market anomalies. Rev. Financ. Stud. 19(3), 1001-1040 (2006)

Avramov, D., Chordia, T., Goyal, A.: Liquidity and autocorrelations in individual stock returns. J. Finance 61(5), 2365-2394 (2006)

Avramov, D., Chordia, T., Jostova, G., Philipov, A.: Momentum and credit rating. J. Finance 62(5), 25032520 (2007)

Bali, T.G., Cakici, N.: Idiosyncratic volatility and the cross section of expected returns. J. Financ. Quant. Anal. 43(1), 29-58 (2008)

Ball, R.: Anomalies in relationships between securities' yields and yield-surrogates. J. Financ. Econ. 6(2), 103-126 (1978)

Ball, R., Brown, P.: An empirical evaluation of accounting income numbers. J. Account. Res. 6(2), 159178 (1968)

Bansal, R., Yaron, A.: Risks for the long run: a potential resolution of asset pricing puzzles. J. Finance 59(4), 1481-1509 (2004)

Bansal, R., Dittmar, R.F., Kiku, D.: Cointegration and consumption risks in equity returns. Rev. Financ. Stud. 22(3), 1343-1375 (2009)

Bansal, R., Dittmar, R.F., Lundblad, C.T.: Consumption, dividends, and the cross section of equity returns. J. Finance 60(4), 1639-1672 (2005)

Banz, R.W.: The relationship between return and market value of common stocks. J. Financ. Econ. 9(1), 3-18 (1981)

Basu, S.: Investment performance of common stocks in relation to their price-earnings ratios: a test of the efficient market hypothesis. J. Finance 12(3), 129-156 (1977)

Beeler, J., Campbell, J.Y.: The long-run risks model and aggregate asset prices: an empirical assessment. NBER working paper 14788 (2011)

Berk, J.B., Green, R.C., Naik, V.: Optimal investment, growth options and security returns. J. Finance 54(5), 1553-1607 (1999)

Bernard, V.L., Thomas, J.K.: Post-earnings-announcement drift: delayed price response or risk premium? J. Account. Res. 27(Supplement 1989), 1-48 (1989)

Bernard, V.L., Thomas, J.K.: Evidence that stock prices do not fully reflect the implications of current earnings for future earnings. J. Account. Econ. 13(4), 305-340 (1990)

Bernardo, A.E., Chowdhry, B., Goyal, A.: Growth options, beta, and the cost of capital. Financ. Manag. 36(2), 1-13 (2007)

Bhandari, L.C.: Debt/equity ratio and expected common stock returns: empirical evidence. J. Finance 43(2), 507-528 (1988)

Black, F.: Capital market equilibrium with restricted borrowing. J. Bus. 45(3), 444-454 (1972)

Black, F., Jensen, M.C., Scholes, M.: The capital asset pricing model: some empirical tests. In: Jensen, M.C. (ed.) Studies in the Theory of Capital Markets, pp. 79-121. Praeger, New York (1972)

Boehme, R.D., Danielsen, B.R., Sorescu, S.M.: Short-sale constraints, differences of opinion, and overvaluation. J. Financ. Quant. Anal. 41(2), 455-487 (2006)

Breeden, D.: An intertemporal asset pricing model with stochastic consumption and investment opportunities. J. Financ. Econ. 7(3), 265-296 (1979)

Breeden, D., Gibbons, M.R., Litzenberger, R.H.: Empirical tests of the consumption-oriented CAPM. J. Finance 44(2), 231-262 (1989)

Brennan, M., Chordia, T., Subrahmanyam, A.: Alternative factor specifications, security characteristics and the cross section of expected stock returns. J. Financ. Econ. 49(3), 345-373 (1998)

Brennan, M., Chordia, T., Subrahmanyam, A., Tong, Q.: Sell-side liquidity and the cross section of expected stock returns. J. Financ. Econ. (2010, forthcoming)

Brennan, M.J., Wang, A.W., Xia, Y.: Estimation and test of a simple model of intertemporal capital asset pricing. J. Finance 59(4), 1743-1775 (2004)

Brunnermeier, M.K., Pedersen, L.H.: Market liquidity and funding liquidity. Rev. Financ. Stud. 22(6), 2201-2238 (2009) 
Campbell, J.Y.: Understanding risk and return. J. Polit. Econ. 104(2), 298-345 (1996)

Campbell, J.Y.: Asset pricing at the millennium. J. Finance 55(4), 1515-1567 (2000)

Campbell, J.Y., Hilscher, J., Szilagyi, J.: In search of distress risk. J. Finance 63(6), 2899-2939 (2008)

Campbell, J.Y., Lo, A.W., MacKinlay, A.C.: The Econometrics of Financial Markets. Princeton University Press, Princeton (1997)

Campbell, J.Y., Polk, C., Vuolteenaho, T.: Growth or glamour? Fundamentals and systematic risk in stock returns. Rev. Financ. Stud. 23(1), 305-344 (2010)

Campbell, J.Y., Vuolteenaho, T.: Bad beta, good beta. Am. Econ. Rev. 94(5), 1249-1275 (2004)

Capaul, C., Rowley, I., Sharpe, W.F.: International value and growth stock returns. Financ. Anal. J. 49(1), 27-36 (1993)

Carhart, M.M.: On persistence in mutual fund performance. J. Finance 52(1), 57-82 (1997)

Carlson, M., Fisher, A., Giammarino, R.: Corporate investment and asset price dynamics: implications for the cross section of returns. J. Finance 59(6), 2577-2603 (2004)

Chan, L.K.C., Lakonishok, J., Sougiannis, T.: The stock market valuation of research and development expenditures. J. Finance 56(6), 2431-2456 (2001)

Chan, L.K.C., Hamao, Y., Lakonishok, J.: Fundamentals and stock returns in Japan. J. Finance 46(5), 1739-1764 (1991)

Chen, J., Hong, H., Stein, J.: Breadth of ownership and stock returns. J. Financ. Econ. 66(2-3), 171-205 (2002)

Chen, N., Roll, R., Ross, S.A.: Economic forces and the stock market. J. Bus. 59(3), 383-404 (1986)

Chui, A.C.W., Titman, S., Wei, K.C.J.: Individualism and momentum around the world. J. Finance 65(1), 361-392 (2010)

Chordia, T., Goyal, A., Shanken, J.: Cross-sectional asset pricing with individual stocks: betas versus characteristics. Working paper (2011)

Chordia, T., Goyal, A., Sadka, G., Sadka, R., Shivakumar, L.: Liquidity and the post-earningsannouncement-drift. Financ. Anal. J. 65(4), 18-32 (2009)

Chordia, T., Roll, R., Subrahmanyam, A.: Commonality in liquidity. J. Financ. Econ. 56(1), 3-28 (2000)

Chordia, T., Shivakumar, L.: Momentum, business cycle, and time-varying expected returns. J. Finance 57(2), 985-1019 (2002)

Cochrane, J.H.: Production-based asset pricing and the link between stock returns and economic fluctuations. J. Finance 46(1), 207-234 (1991)

Cochrane, J.H.: A cross-sectional test of an investment-based asset pricing model. J. Polit. Econ. 104(3), 572-621 (1996)

Cochrane, J.H.: Asset Pricing, 2nd edn. Princeton University Press, Princeton (2005)

Cochrane, J.H.: Discount rates. J. Finance 66(4), 1047-1108 (2011)

Cohen, K.J., Hawawini, G.A., Maier, S.A., Schwartz, R.A., Whitcomb, D.K.: Friction in the trading process and the estimation of systematic risk. J. Financ. Econ. 12(2), 263-278 (1983)

Cohen, R.B., Gompers, P.A., Vuolteenaho, T.: Who underreacts to cash flow news? Evidence from trading between individuals and institutions. J. Financ. Econ. 66(2-3), 409-462 (2002)

Conrad, J., Kaul, G.: Long-term market overreaction or biases in computed returns? J. Finance 48(1), 39-63 (1993)

Connor, G.: A unified beta pricing theory. J. Econ. Theory 34(1), 13-39 (1984)

Connor, G., Korajczyk, R.A.: Performance measurement with the arbitrage pricing theory: a new framework for analysis. J. Financ. Econ. 15(3), 373-394 (1986)

Connor, G., Korajczyk, R.A.: A test for the number of factors in an approximate factor model. J. Financ. Econ. 48(4), 1263-1291 (1993)

Constantinides, G.M., Ghosh, A.: Asset pricing tests with long-run risks in consumption growth. Rev. Asset Pricing Stud. 1(1), 96-136 (2011)

Cooper, I.: Asset pricing implications of nonconvex adjustment costs and irreversibility of investment. J. Finance 61(1), 139-170 (2006)

Cooper, M.J.: Filter rules based on price and volume in individual security overreaction. Rev. Financ. Stud. 12(4), 901-935 (1999)

Cooper, M.J., Gulen, H., Schill, M.J.: Asset growth and the cross section of stock returns. J. Finance 63(4), 1609-1651 (2008)

Cooper, M.J., Gutierrez, R.C., Hammed, A.: Market states and momentum. J. Finance 59(3), 1345-1365 (2004)

Da, Z.: Cash flow, consumption risk, and the cross section of stock returns. J. Finance 64(2), 923-956 (2009) 
Da, Z., Guo, R.-J., Jagannathan, R.: CAPM for estimating the cost of equity capital: interpreting the empirical evidence. J. Financ. Econ. (2011, forthcoming)

Daniel, K., Titman, S.: Evidence on the characteristics of cross-sectional variation in common stock returns. J. Finance 52(1), 1-33 (1997)

Daniel, K., Titman, S.: Market reactions to tangible and intangible information. J. Finance 61(4), 16051643 (2006)

Datar, V.T., Naik, N.Y., Radcliffe, R.: Liquidity and stock returns: an alternative test. J. Financ. Mark. 1(2), 203-219 (1998)

Davis, J., Fama, E.F., French, K.R.: Characteristics, covariances, and average returns: 1929 to 1997. J. Finance 55(1), 389-406 (2000)

De Bondt, W.F.M., Thaler, R.: Does the stock market overreact? J. Finance 40(3), 793-805 (1985)

De Bondt, W.F.M., Thaler, R.: Further evidence on investor overreaction and stock market seasonality. J. Finance 42(3), 557-581 (1987)

Desai, H., Ramesh, K., Thiagarajan, S.R., Balachandran, B.V.: An investigation of the informational role of short interest in the Nasdaq market. J. Finance 57(5), 2263-2287 (2002)

Dichev, I.: Is the risk of bankruptcy a systematic risk? J. Finance 53(3), 1131-1147 (1998)

Diether, K., Malloy, C., Scherbina, A.: Differences of opinion and the cross section of stock returns. J. Finance 57(5), 2113-2141 (2002)

Dimson, E.: Risk measurement when shares are subject to infrequent trading. J. Financ. Econ. 7(2), 197226 (1979)

Douglas, G.W.: Risk in the equity markets: an empirical appraisal of market efficiency. Yale Econ. Essays 9, 3-45 (1969)

Doukas, J.A., McKnight, P.J.: European momentum strategies, information diffusion, and investor conservatism. Eur. Financ. Manag. 11(3), 313-338 (2005)

Duarte, J., Young, L.: Why is PIN priced? J. Financ. Econ. 91(2), 119-138 (2009)

Easley, D., O’Hara, M.: Price, trade size, and information in securities markets. J. Financ. Econ. 19(1), 69-90 (1987)

Easley, D., Kiefer, N.M., O’Hara, M., Paperman, J.B.: Liquidity, information and infrequently traded stocks. J. Finance 51(4), 1405-1436 (1996)

Easley, D., Hvidkjaer, S., O’Hara, M.: Is information risk a determinant of asset returns? J. Finance 57(5), 2185-2221 (2002)

Easley, D., O’Hara, M.: Information and the cost of capital. J. Finance 59(4), 1553-1583 (2004)

Eisdorfer, A., Goyal, A., Zhdanov, A.: Misvaluation and return anomalies in distress stocks. Working paper (2011)

Fama, E.F.: Efficient capital markets: a review of theory and empirical work. J. Finance 25(2), 383-417 (1970)

Fama, E.F.: Market efficiency, long-term returns, and behavioral finance. J. Financ. Econ. 49(3), 283-306 (1998)

Fama, E.F., French, K.R.: Dividend yields and expected stock returns. J. Financ. Econ. 22(1), 3-25 (1988)

Fama, E.F., French, K.R.: The cross section of expected stock returns. J. Finance 47(2), 427-465 (1992)

Fama, E.F., French, K.R.: Common risk factors in the returns on stocks and bonds. J. Financ. Econ. 33(1), 3-56 (1993)

Fama, E.F., French, K.R.: Multifactor explanations of asset pricing anomalies. J. Finance 51(1), 55-84 (1996)

Fama, E.F., French, K.R.: Value versus growth: the international evidence. J. Finance 53(6), 1975-1999 (1998)

Fama, E.F., French, K.R.: The capital asset pricing model: theory and evidence. J. Econ. Perspect. 18(3), 25-46 (2004)

Fama, E.F., French, K.R.: Dissecting anomalies. J. Finance 63(4), 1653-1678 (2008)

Fama, E.F., French, K.R.: Size, value, and momentum in international stock returns. CRSP Working paper No. 11-10 (2011)

Fama, E.F., MacBeth, J.D.: Risk, return and equilibrium: empirical tests. J. Polit. Econ. 81(3), 607-636 (1973)

Ferson, W.E., Harvey, C.R.: The variation of economic risk premiums. J. Polit. Econ. 99(2), 385-415 (1991)

Ferson, W.E., Harvey, C.R.: The risk and predictability of international equity returns. Rev. Financ. Stud. 6(3), 527-566 (1993)

Ferson, W.E., Harvey, C.R.: Conditioning variables and the cross section of stock returns. J. Finance 54(4), 1325-1360 (1999) 
Ferson, W.E., Korajczyk, R.A.: Do arbitrage pricing models explain the predictability of stock returns? J. Bus. 68(3), 309-349 (1995)

Fink, J., Fink, K., He, H.: Idiosyncratic volatility measures and expected return. Working paper (2011). http://ssrn.com/abstract=1692315

Fowler, D.J., Rorke, C.H.: Risk measurement when shares are subject to infrequent trading: comment. J. Financ. Econ. 12(2), 279-283 (1983)

Frankel, R., Lee, C.M.C.: Accounting valuation, market expectation, and cross-sectional stock returns. J. Account. Econ. 25(3), 283-319 (1998)

Fu, F.: Idiosyncratic risk and the cross section of expected stock returns. J. Financ. Econ. 91(1), 24-37 (2009)

Gagliardinia, P., Ossola, E., Scaillet, O.: Time-varying risk premium in large cross-sectional equity datasets. Working paper, Swiss Finance Institute (2011)

Gibbons, M.R., Ross, S.A., Shanken, J.: A test of the efficiency of a given portfolio. Econometrica 57(5), 1121-1152 (1989)

Gomes, J., Kogan, L., Zhang, L.: Equilibrium cross section of returns. J. Polit. Econ. 111(4), 693-732 (2003)

Goyal, A., Wahal, S.: Is momentum an echo? Working paper (2011). http://ssrn.com/abstract=1935601

Graham, B., Dodd, D.: Security Analysis. McGraw-Hill, New York (1934)

Griffin, J.M., Lemmon, M.L.: Book-to-market equity, distress risk, and stock returns. J. Finance 57(5), 2317-2336 (2002)

Grinblatt, M., Titman, S.: Approximate factor structures: interpretations and implications for empirical tests. J. Finance 40(5), 1367-1373 (1985)

Grinblatt, M., Moskowitz, T.J.: Do industries explain momentum? J. Finance 54(4), 1249-1290 (1999)

Griffin, J.M., Ji, X., Martin, J.S.: Momentum investing and business cycle risk: evidence from pole to pole. J. Finance 58(6), 2515-2547 (2003)

Hansen, L.P.: Large sample properties of generalized method of moments estimators. Econometrica 50(4), 1029-1054 (1982)

Hansen, L.P., Heaton, J., Li, N.: Consumption strikes back? Measuring long-run risk. J. Polit. Econ. 116(2), 260-302 (2008)

Hansen, L.P., Jagannathan, R.: Assessing specification errors in stochastic discount factor models. J. Finance 52(2), 557-590 (1997)

Hansen, L.P., Richard, S.F.: The role of conditioning information in deducing testable restrictions implied by dynamic asset pricing models. Econometrica 55(3), 587-613 (1987)

Hasbrouck, J.: Trading costs and returns for US equities: estimating effective costs from daily data. J. Finance 64(3), 1445-1477 (2009)

Hasbrouck, J., Seppi, D.: Common factors in prices, order flows and liquidity. J. Financ. Econ. 59(3), 383-411 (2001)

Haugen, R.A., Baker, N.L.: Commonality in the determinants of expected stock returns. J. Financ. Econ. 41(3), 401-439 (1996)

Heston, S.L., Sadka, R.: Seasonality in the cross section of stock returns. J. Financ. Econ. 87(2), 418-445 (2008)

Hong, H., Lim, T., Stein, J.C.: Bad news travels slowly: size, analyst coverage, and the profitability of momentum strategies. J. Finance 55(1), 265-295 (2000)

Hou, K., Karolyi, G.A., Kho, B.-C.: What factors drive global stock returns? Rev. Financ. Stud. 24(8), 2527-2574 (2011)

Hou, K., Moskowitz, T.J.: Market frictions, delay, and the cross section of expected returns. Rev. Financ. Stud. 18(3), 981-1020 (2005)

Huang, W., Liu, Q., Rhee, S.G., Zhang, L.: Return reversals, risk, and expected returns. Rev. Financ. Stud. 23(1), 147-168 (2010)

Huberman, G., Halka, D.: Systematic liquidity. J. Financ. Res. 24(2), 161-178 (2001)

Hvidkjaer, S.: A trade-based analysis of momentum. Rev. Financ. Stud. 19(2), 457-491 (2006)

Ikenberry, D., Lakonishok, J., Vermaelen, T.: Market underreaction to open market share repurchases. J. Financ. Econ. 39(2-3), 181-208 (1995)

Jacobs, K., Wang, K.Q.: Idiosyncratic consumption risk and the cross section of asset returns. J. Finance 59(5), 2211-2252 (2004)

Jagannathan, R., Schaumburg, E., Zhou, G.: Cross-sectional asset pricing tests. Ann. Rev. Financ. Econ. 2, 49-74 (2010a)

Jagannathan, R., Skoulakis, G., Wang, Z.: The analysis of the cross section of security returns. In: AïSahalia, Y., Hansen, L.P. (eds.) Handbook of Financial Econometrics, vol. 2, pp. 73-134 (2010b) 
Jagannathan, R., Wang, Y.: Lazy investors, discretionary consumption, and the cross section of stock returns. J. Finance 62(4), 1623-1661 (2007)

Jagannathan, R., Wang, Z.: The conditional CAPM and the cross section of expected returns. J. Finance 51(1), 3-53 (1996)

Jagannathan, R., Wang, Z.: An asymptotic theory for estimating beta-pricing models using cross-sectional regressions. J. Finance 53(4), 1285-1309 (1998)

Jagannathan, R., Wang, Z.: Empirical evaluation of asset-pricing models: a comparison of the SDF and beta methods. J. Finance 57(5), 2337-2367 (2002)

Jegadeesh, N.: Evidence of predictable behavior of security returns. J. Finance 45(3), 881-898 (1990)

Jegadeesh, N., Titman, S.: Returns to buying winners and selling losers: implications for stock market efficiency. J. Finance 48(1), 65-92 (1993)

Jegadeesh, N., Titman, S.: Profitability of momentum strategies: an evaluation of alternative explanations. J. Finance 56(2), 699-720 (2001)

Jensen, M.C.: The performance of mutual funds in the period 1945-1964. J. Finance 23(2), 389-416 (1968)

Jobson, J.D., Korkie, B.M.: Some tests of linear asset pricing with multivariate normality. Can. J. Adm. Sci. 2(1), 114-138 (1985)

Jones, C.M., Lamont, O.A.: Short-sale constraints and stock returns. J. Financ. Econ. 66(2-3), 202-239 (2002)

Kandel, S.: The likelihood ratio test statistic of mean-variance efficiency without a riskless asset. J. Financ. Econ. 13(4), 575-592 (1984)

Kandel, S., Stambaugh, R.F.: On correlations and inferences about mean-variance efficiency. J. Financ. Econ. 18(1), 61-90 (1987)

Kan, R., Robotti, C., Shanken, J.: Two-pass cross-sectional regressions under potentially misspecified models. Working paper (2011)

Kapadia, N.: Tracking down distress risk. J. Financ. Econ. 102(1), 167-182 (2011)

Kim, D.: The errors in the variables problem in the cross section of expected stock returns. J. Finance 50(5), 1605-1634 (1995)

Korajczyk, R.A., Sadka, R.: Pricing the commonality across alternative measures of liquidity. J. Financ. Econ. 87(1), 45-72 (2008)

La Porta, R.: Expectations and the cross section of stock returns. J. Finance 51(5), 1715-1742 (1996)

Lakonishok, J., Shleifer, A., Vishny, R.W.: Contrarian investment, extrapolation, and risk. J. Finance 49(5), 1541-1578 (1994)

Lee, C.M.C., Myers, J., Swaminathan, B.: What is the intrinsic value of Dow? J. Finance 54(5), 1693-1741 (1999)

Lehmann, B.N.: Fads, martingales, and market efficiency. Q. J. Econ. 105(1), 1-28 (1990)

Lehmann, B.N., Modest, D.M.: The empirical foundations of the arbitrage pricing theory. J. Financ. Econ. 21(2), 213-254 (1988)

Lehmann, B.N., Modest, D.M.: Optimal construction of basis portfolios. Manag. Sci. 51(4), 581-598 (2005)

Levy, H.: Equilibrium in an imperfect market: a constraint on the number of securities in the portfolio. Am. Econ. Rev. 68(4), 643-658 (1978)

Lewellen, J.W., Nagel, S., Shanken, J.: A skeptical appraisal of asset pricing tests. J. Financ. Econ. 96(2), 175-194 (2010)

Lettau, M., Ludvigson, S.: Consumption, aggregate wealth and expected stock returns. J. Finance 56(3), 815-849 (2001a)

Lettau, M., Ludvigson, S.: Resurrecting the (C)CAPM: a cross-sectional test when risk premia are timevarying. J. Polit. Econ. 109(6), 1238-1287 (2001b)

Li, D., Zhang, L.: Does q-theory with investment frictions explain anomalies in the cross section of returns? J. Financ. Econ. 98(2), 297-314 (2010)

Li, E.X.N., Livdan, D., Zhang, L.: Anomalies. Rev. Financ. Stud. 22(11), 4301-4334 (2009)

Liew, J., Vassalou, M.: Can book-to-market, size and momentum be risk factors that predict economic growth? J. Financ. Econ. 57(2), 221-245 (2000)

Lintner, J.: The valuation of risk assets and the selection of risky investments in stock portfolios and capital budgets. Rev. Econ. Stat. 47(1), 13-37 (1965a)

Lintner, J.: Security prices, risk and maximal gains from diversification. J. Finance 20(4), 587-616 (1965b)

Lipson, M., Mortal, S., Schill, M.: On the scope and drivers of the asset growth effect. J. Financ. Quant. Anal. (2010). doi:10.1017/S0022109011000561 
Litzenberger, R.H., Ramaswamy, K.: The effect of personal taxes and dividends on capital asset prices: theory and empirical evidence. J. Financ. Econ. 7(2), 163-196 (1979)

Liu, L.X., Whited, T.M., Zhang, L.: Investment-based expected stock returns. J. Polit. Econ. 117(6), 11051139 (2009)

Liu, L.X., Zhang, L.: Momentum profits, factor pricing, and macroeconomic risk. Rev. Financ. Stud. 21(6), 2417-2448 (2008)

Livdan, D., Sapriza, H., Zhang, L.: Financially constrained stock returns. J. Finance 64(4), 1827-1862 (2009)

Lo, A., MacKinlay, A.C.: Stock market prices do not follow random walks: evidence from a simple specification test. Rev. Financ. Stud. 1(1), 41-66 (1988)

Loughran, T., Ritter, J.R.: The new issues puzzle. J. Finance 50(1), 23-51 (1995)

Loughran, T., Ritter, J.R.: Long-term market overreaction: the effect of low-priced stocks. J. Finance 51(5), 1959-1970 (1996)

Malkiel, B.G., Xu, Y.: Risk and return revisited. J. Portf. Manag. 23(1), 9-14 (1997)

Malkiel, B.G., Xu, Y.: Idiosyncratic risk and security returns. Working paper, University of Texas at Dallas (2002)

Malloy, C.J., Moskowitz, T.J., Vissing-Jorgensen, A.: Long-run stockholder consumption risk and asset returns. J. Finance 64(4), 2427-2479 (2009)

Mehra, R., Prescott, E.C.: The equity premium: a puzzle. J. Monet. Econ. 15(2), 145-161 (1985)

Mehra, R. (ed.): Handbook of the Equity Risk Premium. Elsevier, North-Holland, Amsterdam (2008)

Merton, R.C.: An intertemporal capital asset pricing model. Econometrica 41(5), 867-887 (1973)

Merton, R.C.: A simple model of capital market equilibrium with incomplete information. J. Finance 42(3), 483-510 (1987)

Miller, E.M.: Risk, uncertainty and divergence of opinion. J. Finance 32(4), 1151-1168 (1977)

Miller, M.M., Scholes, M.: Rates and return in relation to risk: a re-examination of some recent findings. In: Jensen, M.C. (ed.) Studies in the Theory of Capital Markets, pp. 47-78. Praeger, New York (1972)

Moskowitz, T.J., Ooi, Y.H., Pedersen, L.H.: Time-series momentum. J. Financ. Econ. (2010). doi:10.1016/ j.jfineco.2011.11.003

Mossin, J.: Equilibrium in a capital asset market. Econometrica 34(4), 768-783 (1966)

Nagel, S.: Short sales, institutional investors and the cross section of stock returns. J. Financ. Econ. 78(2), 277-309 (2005)

Newey, W.K., West, K.D.: A simple, positive semi-definite, heteroskedasticity, and autocorrelation consistent covariance matrix. Econometrica 55(3), 703-708 (1987)

Novy-Marx, R.: Is momentum really momentum? J. Financ. Econ. (2010). doi:10.1016/j.jfineco. 2011.05.003

Parker, J.A., Julliard, C.: Consumption risk and the cross section of expected returns. J. Polit. Econ. 113(1), 185-222 (2005)

Pástor, Ľ., Stambaugh, R.F.: Liquidity risk and expected stock returns. J. Polit. Econ. 111(3), 642-685 (2003)

Petkova, R.: Do the Fama-French factors proxy for innovations in predictive variables? J. Finance 61(2), 581-612 (2006)

Piotroski, J.D.: Value investing: the use of historical financial statement information to separate winners from losers. J. Account. Res. 38(Supplement 2000), 1-41 (2000)

Pontiff, J., Woodgate, A.: Share issuance and cross-sectional returns. J. Finance 63(2), 921-945 (2008)

Roll, R.R.: A critique of the asset pricing theory's tests part I: on past and potential testability of the theory. J. Financ. Econ. 4(2), 129-176 (1977)

Roll, R.R., Ross, S.A.: A critical reexamination of the arbitrage pricing theory: a reply. J. Finance 39(2), 347-350 (1984)

Rosenberg, B., Guy, J.: Prediction of beta from investment fundamentals. Financ. Anal. J. 32(3), 60-72 (1976)

Rosenberg, B., Reid, K., Lanstein, R.: Persuasive evidence of market inefficiency. J. Portf. Manag. 11(Spring), 9-17 (1985)

Ross, S.A.: The arbitrage theory of capital asset pricing. J. Econ. Theory 13(3), 341-360 (1976)

Rouwenhorst, G.K.: International momentum strategies. J. Finance 53(1), 267-284 (1998)

Santos, T., Veronesi, P.: Labor income and predictable stock returns. Rev. Financ. Stud. 19(1), 1-44 (2006)

Savov, A.: Asset pricing with garbage. J. Finance 66(1), 177-201 (2011)

Scholes, M., Williams, J.: Estimating betas from nonsynchronous data. J. Financ. Econ. 5(3), 309-327 (1977) 
Sharpe, W.: Capital asset prices: a theory of market equilibrium under conditions of risk. J. Finance 19(3), 425-442 (1964)

Shanken, J.: The arbitrage pricing theory: is it testable? J. Finance 37(5), 1129-1140 (1982)

Shanken, J.: Multi-beta CAPM or equilibrium-APT? A reply. J. Finance 40(4), 1189-1196 (1985a)

Shanken, J.: Multivariate tests of the zero-beta CAPM. J. Financ. Econ. 14(3), 327-348 (1985b)

Shanken, J.: Testing portfolio efficiency when the zero-beta rate is unknown: a note. J. Finance 41(1), 269-276 (1986)

Shanken, J.: Multivariate proxies and asset pricing relations: living with the roll critique. J. Financ. Econ. 18(1), 91-110 (1987)

Shanken, J.: The current state of the arbitrage pricing theory. J. Finance 47(4), 1569-1574 (1992a)

Shanken, J.: On the estimation of beta-pricing models. Rev. Financ. Stud. 5(1), 1-33 (1992b)

Shanken, J., Weinstein, M.I.: Economic forces and the stock market revisited. J. Empir. Finance 13(2), 109-144 (2006)

Shanken, J., Zhou, G.: Estimating and testing beta-pricing models: alternative methods and their performance in simulations. J. Financ. Econ. 84(1), 40-86 (2007)

Sloan, R.: Do stock prices fully reflect information in accruals and cash flows about future earnings? Account. Rev. 71(3), 289-315 (1996)

Sorescu, S.M., Subrahmanyam, A.: The cross section of analyst recommendations. J. Financ. Quant. Anal. 41(1), 139-168 (2006)

Stambaugh, R.F.: On the exclusion of assets from tests of the two-parameter model: a sensitivity analysis. J. Financ. Econ. 10(3), 237-268 (1982)

Stattman, D.: Book values and stock returns. Chicago MBA J. Sel. Pap. 4, 25-45 (1980)

Subrahmanyam, A.: The cross section of expected stock returns: what have we learnt from the past twentyfive years of research? Eur. Financ. Manag. 16(1), 27-42 (2010)

Titman, S., Wei, K.C.J., Xie, F.: Capital investments and stock returns. J. Financ. Quant. Anal. 39(4), 677-700 (2004)

Titman, S., Wei, K.C.J., Xie, F.: Access to equity markets, corporate investments and stock returns: international evidence. Working paper (2010)

Vassalou, M.: News related to future GDP growth as a risk factor in equity returns. J. Financ. Econ. 68(1), 47-73 (2003)

Watanabe, A., Xu, Y., Yao, T., Yu, T.: The asset growth effect: insights from international equity markets. Working paper (2011). http://ssrn.com/abstract=1787237

Womack, K.: Do brokerage analysts' recommendations have investment value? J. Finance 51(1), 137-167 (1996)

Xing, Y.: Interpreting the value effect through the q-theory: an empirical investigation. Rev. Financ. Stud. 21(4), 1767-1795 (2008)

Yogo, M.: A consumption-based explanation of expected stock returns. J. Finance 61(2), 539-580 (2006)

Zhang, L.: The value premium. J. Finance 60(1), 67-103 (2005)

Amit Goyal is a Professor of Finance at HEC Lausanne and holds a Senior Chair at the Swiss Finance Institute. Formerly on the faculty of Emory University (Atlanta, USA), he holds a Ph.D. in Finance from University of California at Los Angeles. His research interests are in empirical asset pricing, predictability of stock returns, portfolio optimization, and pension funds. 